\title{
Endocytosis and Degradative Sorting of NMDA Receptors by Conserved Membrane-Proximal Signals
}

\author{
Derek B. Scott, ${ }^{1,2}$ Ioannis Michailidis, ${ }^{6}$ Yuanyue Mu, ${ }^{3}$ Diomedes Logothetis, ${ }^{6}$ and Michael D. Ehlers ${ }^{2,3,4,5}$ \\ ${ }^{1}$ Program in Cell and Molecular Biology, Departments of ${ }^{2}$ Cell Biology, ${ }^{3}$ Neurobiology, ${ }^{4}$ Pharmacology and Cancer Biology, and ${ }^{5}$ Neuroproteomics \\ Laboratory, Duke University Medical Center, Durham, North Carolina 27710, and ${ }^{6}$ Department of Physiology and Biophysics, Mount Sinai School of \\ Medicine, New York, New York 10029
}

\begin{abstract}
Regulation of the abundance of NMDA receptors (NMDARs) at excitatory synapses is critical during changes in synaptic efficacy underlying learning and memory as well as during synapse formation throughout neural development. However, the molecular signals that govern NMDAR delivery, maintenance, and internalization remain unclear. In this study, we identify a conserved family of membraneproximal endocytic signals, two within the NMDAR type 1 (NR1) subunit and one within the NR2A and NR2B subunits, necessary and sufficient to drive the internalization of NMDARs. These endocytic motifs reside in the region of NMDAR subunits immediately after the fourth membrane segment, a region implicated in use-dependent rundown and NMDA channel inactivation. Although endocytosis driven by the distal C-terminal domain of NR2B is followed by rapid recycling, internalization mediated by membrane-proximal motifs selectively targets receptors to late endosomes and accelerates degradation. These results define a novel conserved signature of NMDARs regulating internalization and postendocytic trafficking.
\end{abstract}

Key words: NMDA receptor; endocytosis; late endosome; excitatory synaptic transmission; synaptic plasticity; intracellular trafficking

\section{Introduction}

The regulated insertion and removal of postsynaptic receptors is essential for altering synaptic transmission during experiencedependent plasticity (Carroll et al., 2001; Carroll and Zukin, 2002; Kneussel, 2002; Bredt and Nicoll, 2003; Wenthold et al., 2003). At excitatory glutamatergic synapses, the insertion of ionotropic glutamate receptors accompanies long-term potentiation (LTP), whereas clathrin-mediated endocytosis of resident glutamate receptors leads to long-term depression (LTD) (Malinow and Malenka, 2002; Bredt and Nicoll, 2003; Wenthold et al., 2003). Although many studies have focused on the trafficking of AMPA-type glutamate receptors (AMPARs) during synaptic plasticity (Malinow and Malenka, 2002; Bredt and Nicoll, 2003), it has become increasingly apparent that dynamic regulation of NMDA receptors (NMDARs) contributes to synapse maturation (Friedman et al., 2000; Washbourne et al., 2002; Bresler et al., 2004), activity-dependent synaptic plasticity (Rao and Craig,

\footnotetext{
Received March 3, 2004; revised June 17, 2004; accepted June 22, 2004.

This work was supported by National Institute on Alcohol Abuse and Alcoholism Grant F31 AA13220 to D.B.S. National Institutes of Health Grants NS39402 and MH64748 to M.D.E., the American Heart Association, the Ellison Medical Foundation, and a Broad Scholar Award in Neuroscience. We thank Drs. Richard Huganir, Pietro De Camilli, Stefano Vicini, Isabel Perez-Otaño, Marino Zerial, Robert Edwards, and Pierre Cosson for providing cDNA constructs used in this study. We also thank Irina Lebedeva, Chi Zhang, and Haiwei Zhang for excellent technical support. In addition, we thank Tom Blanpied, Daniel Gitler, Juliet Hernandez, April Horton, Larry Katz, Richard Mooney, and Isabel Perez-0taño for insightful comments and helpful discussion in preparing this manuscript.

Correspondence should be addressed to Dr. Michael D. Ehlers, Department of Neurobiology, P.0. Box 3209, Duke University Medical Center, Durham, NC 27710. E-mail: ehlers@neuro.duke.edu.

DOI:10.1523/JNEUROSCI.0780-04.2004

Copyright $\odot 2004$ Society for Neuroscience $\quad$ 0270-6474/04/247096-14\$15.00/0
}

1997; Turrigiano et al., 1998; Liao et al., 1999; Quinlan et al., 1999; Watt et al., 2000; Snyder et al., 2001; Barria and Malinow, 2002; Carroll and Zukin, 2002; Grosshans et al., 2002; Montgomery and Madison, 2002), and use-dependent downregulation, which refers to the decline of NMDAR responses after repeated or sustained agonist application (Rosenmund and Westbrook, 1993a,b; Wang et al., 1993; Vissel et al., 2001; Li et al., 2002; Nong et al., 2003). However, the signals used by NMDARs during synaptic insertion and internalization and the cellular mechanisms that underlie the stabilization and trafficking of NMDARs at synaptic sites are poorly understood.

Endocytosis and removal of NMDARs from the plasma membrane occurs during synapse maturation (Roche et al., 2001; Barria and Malinow, 2002), during paradigms of LTD (Snyder et al., 2001), and in response to ligand binding (Vissel et al., 2001; Barria and Malinow, 2002; Li et al., 2002; Nong et al., 2003). Control over NMDAR endocytosis (and NMDAR synaptic targeting generally) has been thought to reside within distal intracellular domains of NMDAR type 2 (NR2) subunits. For example, the distal C terminus of NR2B contains an endocytic motif regulated by the binding of the postsynaptic PDZ [postsynaptic density-95 (PSD-95)/Discs large/zona occludens-1] scaffold protein PSD-95 (Roche et al., 2001). In contrast, agonist binding triggers NMDAR endocytosis (Li et al., 2002; Nong et al., 2003) and usedependent rundown or synaptic replacement independent of ion flux (Vissel et al., 2001; Barria and Malinow, 2002), suggesting conformation-dependent internalization signals coupled to ligand binding or channel gating. Notably, NR1 subunits are obligatory for channel function and contain membrane-proximal cytoplasmic domains linked to channel gating (Ehlers et al., 1996; 


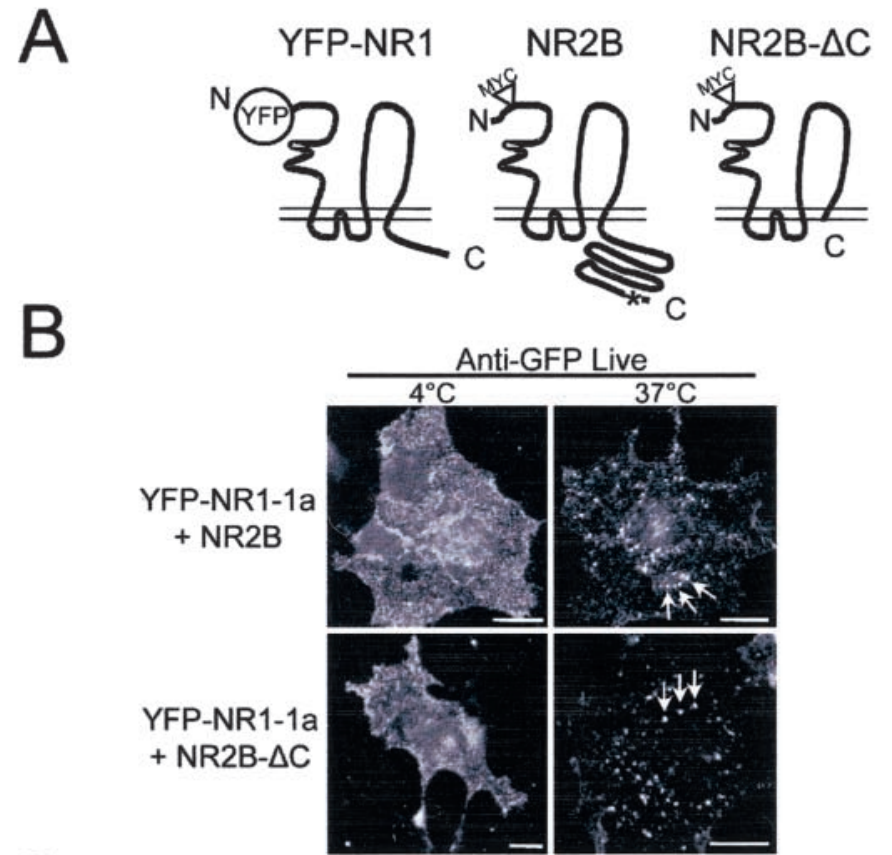

$\mathcal{C}$
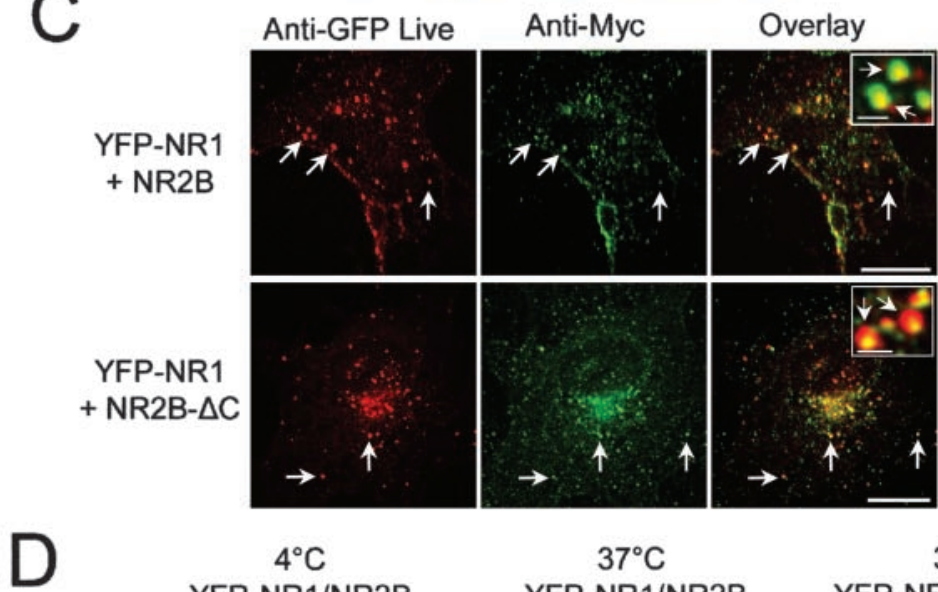

$4^{\circ} \mathrm{C}$

$37^{\circ} \mathrm{C}$

$37^{\circ} \mathrm{C}$
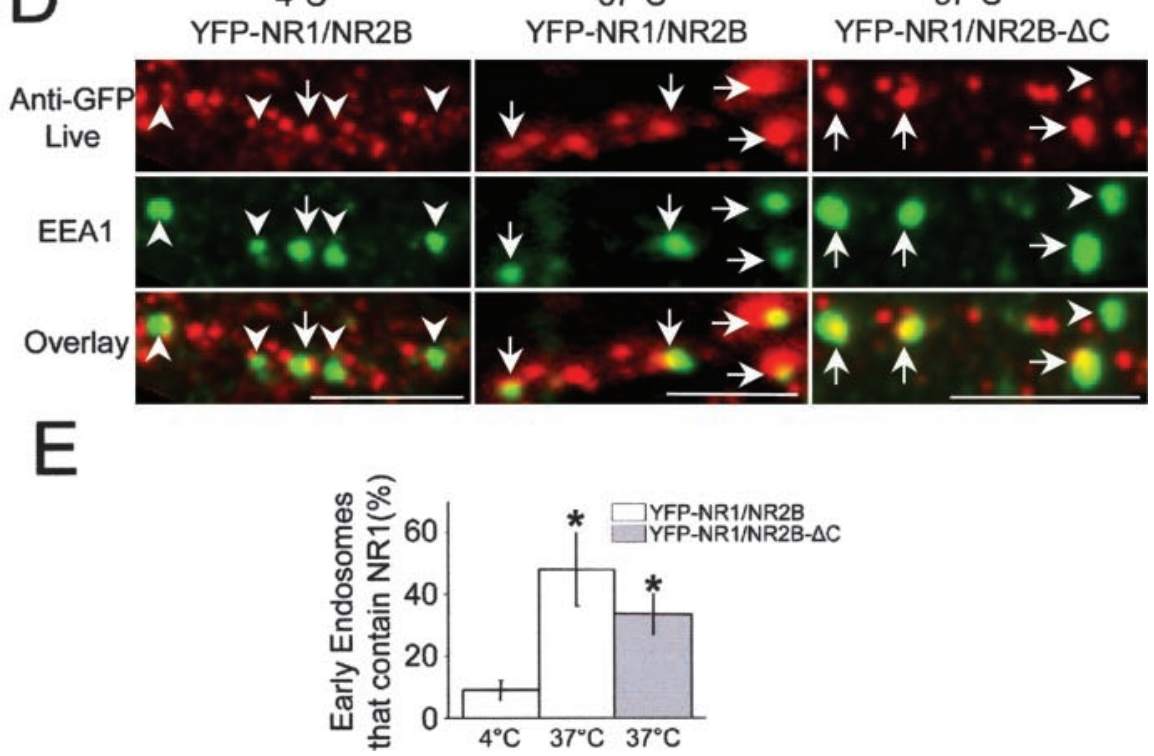

Figure 1. The NMDAR subunit NR1 mediates endocytosis in the absence of NR2 $C$-terminal domains. $A$, YFP was fused to the N terminus of NR1-1a or NR1-4a and coexpressed with myc-tagged wild-type (NR2B) or mutant NR2B subunits (NR2B- $\Delta C$ ) lacking the intracellular domain following fourth membrane domain. The asterisk denotes the position of a known distal endocytic motif, YEKL, within NR2B subunits. $B$, COS7 cells coexpressing YFP-NR1-1a and either wild-type NR2B (top) or NR2B- $\Delta$ C subunits (bottom) were incubated live for 30 min with an anti-GFP antibody either at $4^{\circ} \mathrm{C}$ (left) or $37^{\circ} \mathrm{C}$ (right). Small vesicular puncta of NMDARs (arrows) were observed only when cells were incubated at $37^{\circ} \mathrm{C}$ to allow endocytosis. Scale bars, $10 \mu \mathrm{m}$. C, COS7 cells coexpressing YFP-NR1-4a (YFP-NR1) and either wild-type NR2B (top) or mutant NR2B- $\Delta$ C subunits (bottom) were incubated live with an anti-GFP antibody for $30 \mathrm{~min}$ at $37^{\circ} \mathrm{C}$ to allow endocytosis, fixed, permeabilized, and stained with an anti-myc antibody to visualize NR2B subunits. Note that live-labeled NR1 subunits (red) always colocalized (arrows) with either full-length or C-terminal truncated myc-NR2B (green) in endocytic vesicles. Scale bars, $10 \mu \mathrm{m}$; inset, $1 \mu \mathrm{m}$. D, Hippocampal neurons (10-14 DIV) coexpressing YFP-NR1-4a (YFP-NR1) and wild-type NR2B (left, middle) or NR2B- $\Delta C$ (right) were incubated live for 15 min with an anti-GFP antibody either at $4^{\circ} \mathrm{C}$ (left) or $37^{\circ} \mathrm{C}$ (middle, right), fixed, permeabilized, and stained with an anti-EEA1 antibody to visualize early endosomes. Arrows indicate EEA1-positive endosomes that contain live-labeled NMDARs. Arrowheads indicate EEA1-positive endosomes that do not contain live-labeled NMDARs. Scale bars, $5 \mu \mathrm{m}$. E, Quantification of the percentage of EEA1-positive endosomes that contain internalized NMDARs in hippocampal neurons from $D$. Data represent means \pm SEM; ${ }^{*} p<0.05$ relative to $4^{\circ} \mathrm{C} ; t$ test. $C$, C terminus; $\mathrm{N}, \mathrm{N}$ terminus. 
Zhang et al., 1998; Krupp et al., 1999). However, the role of NR1 subunits in NMDAR endocytosis and membrane removal remains unknown. Moreover, little is known about the fate of internalized NMDARs after endocytosis.

In this study, we investigated the contribution of NR1 subunits to NMDAR internalization. We demonstrate that the membrane-proximal $\mathrm{C} 0$ domain of NR1 contains two independent endocytic signals necessary and sufficient to drive the internalization of NMDARs. Similar endocytic motifs are found within corresponding regions of NR2 subunits, establishing a conserved membrane-proximal endocytic ring near the channel pore. C-terminal domains of NR1 and NR2 contribute in an additive manner to endocytosis but exert distinct effects on postendocytic trafficking. Whereas distal C-terminal regions of NR2B mediate rapid recycling, membrane-proximal signals direct internalized receptors to late endosomes for accelerated degradation. These findings define a novel set of motifs mediating NMDAR internalization, strongly implicate the NR1 subunit in NMDAR endocytosis, and demonstrate that the postendocytic trafficking of NMDARs for degradation or recycling is coordinated by distinct proximal and distal domains of NMDAR subunits. In addition, these results suggest that mechanisms for NMDAR channel regulation and membrane trafficking converge on membrane-proximal segments of NMDAR subunits.

\section{Materials and Methods}

Molecular biology and DNA transfection. Yellow fluorescent protein (YFP)-NR1-1 was kindly provided by Dr. Stefano Vicini (Georgetown University, Washington, DC). YFP-NR1-4 was made as described previously (Mu et al., 2003). Wild-type Myc-NR2B (NR2B) and mutant Myc-NR2B (NR2B- $\Delta$ C) were kindly provided by Dr. Richard Huganir (Johns Hopkins University, Baltimore, MD). Green fluorescent protein (GFP)-Rab5 and GFP-Rab7 were kindly provided by Dr. Marino Zerial (Max Planck Institute, Dresden, Germany). Wildtype and mutant GFP-dynamin-1 was kindly provided by Dr. Pietro De Camilli (Yale University, New Haven, CT). Tac pCDM8 expression vector was kindly provided by Dr. Pierre Cosson (Centre Medical Universitaire, Geneva, Switzerland). Tac-NR2A was kindly provided by Dr. Isabel Perez-Otano (Duke University, Durham, NC). Tac-vesicular monoamine transporter (VMAT) was kindly provided by Dr. Robert Edwards (University of California San Francisco, San Francisco, CA). Tac-NR1 chimeric receptors were generated as reported previously (Scott et al., 2001). Tac-C0 and TacNR2A point mutants were generated using the Quick Change site-directed mutagenesis kit
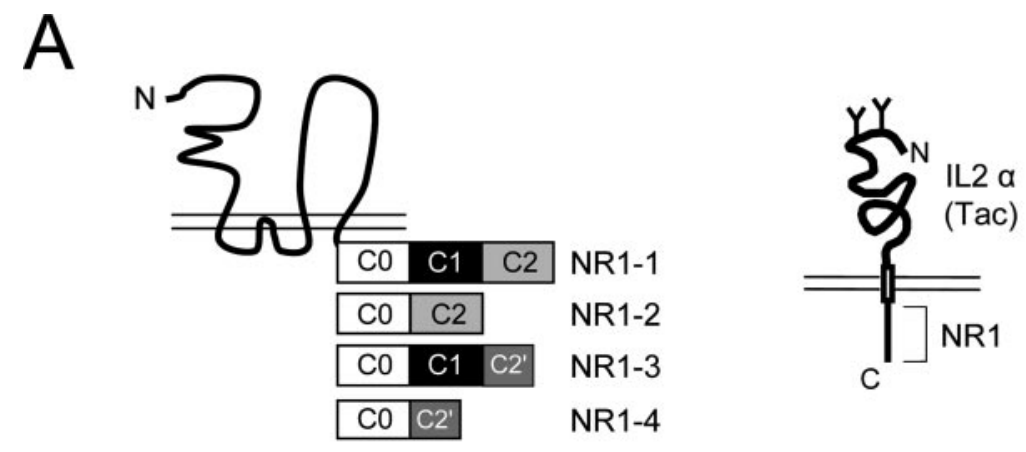

\section{B}
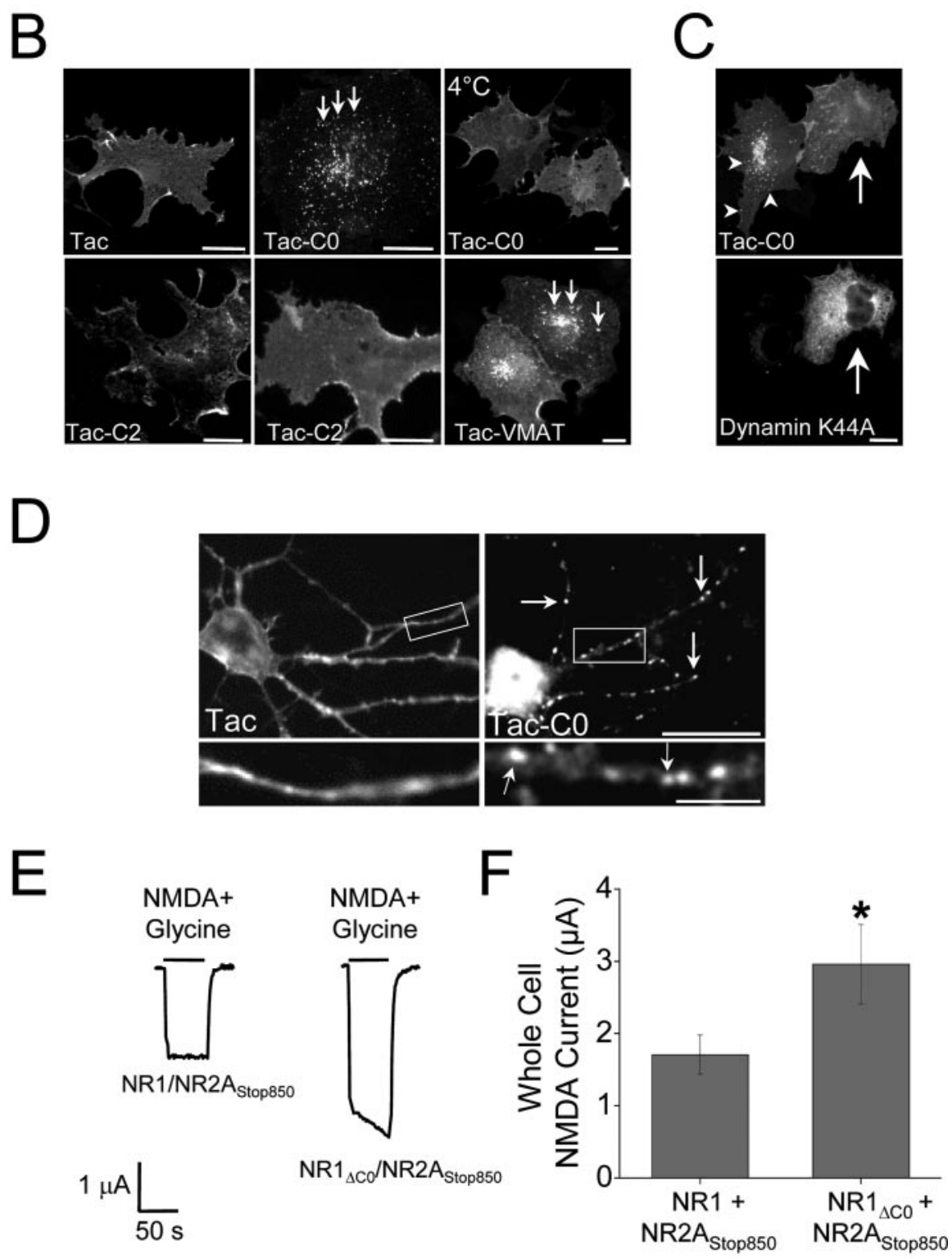

Figure 2. The CO domain of NR1 is sufficient to drive endocytosis. $A$, Schematic representation of NR1 splice variant C-terminal domains and Tac chimeras. $B$, The $C 0$ domain of NR1 contains an endocytic signal. COS7 cells expressing Tac, Tac-CO, Tac- $C 2$, Tac-C2' , or Tac-VMAT were incubated live for $30 \mathrm{~min}$ at $37^{\circ} \mathrm{C}$ or at $4^{\circ} \mathrm{C}$ with an anti-Tac antibody. Only Tac-CO and Tac-VMAT redistribute into small intracellular vesicles (arrows) when incubated at $37^{\circ} \mathrm{C}$. Scale bars, $10 \mu \mathrm{m}$. C, Internalization driven by the $\mathrm{CO}$ domain of NR1 is dynamin dependent. Internalization assays using an anti-Tac antibody were performed for 30 min on COS7 cells expressing Tac-CO (top panel) and a GFP-dynamin dominant-negative mutant (K44A) (bottom panel). In cells that express GFP-dynamin-K44A, Tac-CO is expressed diffusely on the plasma membrane (arrow). Arrowheads indicate internalized receptors in a Tac-CO-expressing cell that lacks GFP-dynamin-K44A expression. Scale bar, $10 \mu \mathrm{m}$. D, The CO domain drives the internalization of chimeric receptors in neurons. Hippocampal neurons (10 DIV) expressing either Tac (left) or Tac-CO (right) were incubated live for 30 min with an anti-Tac antibody. C0-containing receptors internalize into vesicular puncta (arrows), whereas Tac remains diffusely expressed over the plasma membrane. Bottom panels correspond to the region in the (Figure legend continues.) 
(Invitrogen, Carlsbad, CA) following the instructions of the manufacturer. NR1 $\Delta_{\mathrm{C} 0}$ was constructed using the splice by overlap PCR method to delete amino acids $838-863$ of NR1. NR1 $\Delta_{\mathrm{C} 0}$ and NR2 $\mathrm{A}_{\text {Stop } 850}$ were subcloned into $\mathrm{XhoI}$-XbaI sites of the high expression vector pGEMsh for expression in Xenopus oocytes. cRNAs were transcribed using an in vitro transcription kit with the T7 promoter (Ambion, Austin, TX). All constructs were verified by sequencing. COS7 cells, and cultured hippocampal neurons were cultured and transfected as described previously (Scott et al., 2001).

Immunofluorescence and internalization-recycling assays. Monoclonal anti-Tac antibody (1:500; Covance, Princeton, NJ), chicken anti-GFP (1:1000; Chemicon, Temecula, CA), monoclonal anti-Myc (1:100; Covance), monoclonal anti-synapsin (1:1000), and monoclonal anti-early endosome antigen 1 (EEA1) (1:100; BD Bioscience, San Diego, CA) were used for surface expression and internalization assays. All secondary antibodies were used at 1:200 (Jackson ImmunoResearch, West Grove, PA, or Molecular Probes, Eugene, OR).

Internalization assays were accomplished as follows. Transfected cells or 7-14 d in vitro (DIV) cultured hippocampal neurons were incubated live with anti-Tac, anti-GFP, or transferrin Alexa 546 (Molecular Probes) plus anti-Tac antibodies at $4^{\circ} \mathrm{C}$ for up to $1 \mathrm{hr}$ before cells were incubated at $37^{\circ} \mathrm{C}$ for $15 \mathrm{~min}$ to $1 \mathrm{hr}$ to allow internalization. Cells were then fixed $(4 \%$ paraformaldehyde and $4 \%$ sucrose), washed, and permeabilized ( $0.2 \%$ Triton X-100 or $0.4 \%$ saponin for EEA1 colocalization in neurons and colocalization of Tac receptors with GFP-Rabs). Next, cells were incubated with

Surface expression of Tac receptors and NMDAR subunits was accomplished as described above, except that cells were kept at $4^{\circ} \mathrm{C}$ until fixation and permeabilization. For colocalization of internalized YFP-NR1/ NR2 subunits in COS7 cells, internalization assays were performed, and after fixation and permeabilization, cells were incubated with an antimyc antibody for $2 \mathrm{hr}$ at room temperature.

Recycling assays of NMDARs in neurons were accomplished as follows. Ten to 14 DIV hippocampal neurons expressing tagged NMDAR subunits were incubated with an anti-GFP antibody at $4^{\circ} \mathrm{C}$ for $30 \mathrm{~min}$ and then incubated at $37^{\circ} \mathrm{C}$ for $30 \mathrm{~min}$ to allow for internalization of receptors. Surface-bound primary antibody was then acid stripped $(0.5 \mathrm{M}$ $\mathrm{NaCl}$ and $0.2 \mathrm{M}$ acetic acid) for $2 \mathrm{~min}$ at $4^{\circ} \mathrm{C}$, and neurons were incubated with excess unconjugated secondary antibody to block all surface receptors. Neurons were then incubated at $37^{\circ} \mathrm{C}$ for $1 \mathrm{hr}$ in the presence of fluorophore-conjugated secondary antibody to visualize internalized receptors that had recycled back to the plasma membrane. Cells were then fixed, permeabilized $(0.1 \%$ Triton X-100), and incubated with a second fluorescent secondary antibody to visualize internalized receptors that had failed to recycle back to the plasma membrane. The average fluorescence of recycled receptors and internalized receptors was then determined and plotted as a ratio (recycling index). To determine the colocalization of recycled receptors and synapsin, neurons were treated as described above, except that an anti-synapsin antibody was added after permeabilization of neurons. Recycled receptors were designated as colocalized with synapsin puncta if both were either closely juxtaposed $(<0.5 \mu \mathrm{m})$ or overlapped in any way.

Simultaneous staining of surface and internalized receptors used to quantify internalization of NMDARs in neurons was accomplished as described above, except that cells were incubated for $15 \mathrm{~min}$ at $37^{\circ} \mathrm{C}$ to drive internalization of receptors and then quickly fixed before incubation at room temperature for $1 \mathrm{hr}$ with secondary antibody under nonpermeant conditions to visualize surface receptors. Neurons were then permeabilized $(0.1 \%$ Triton) and incubated with a second secondary secondary antibodies, washed, and mounted on slides.

antibody to visualize internalized receptors. The average intensity of internalized and surface receptors was then determined and plotted as a ratio (internalized/surface) before being normalized to the NR1/NR2 internalized/surface ratio

Surface and intracellular expression was visualized on an inverted microscope (Nikon, Melville, NY). Images were acquired through a Yokogawa spinning-disk confocal microscope (Solamere Technology Group, Salt Lake City, UT), using $40 \times, 60 \times$, or $100 \times$ Plan Apochromat objectives and a 12-bit cooled CCD camera (Hamamatsu, Bridgewater, $\mathrm{NJ}$ ) and then analyzed using MetaMorph (Universal Imaging, Downingtown, PA). Images presented are maximal projections of confocal sections taken through the entire cell or neuron.

Quantification of internalization. Quantification of YFP-NR1 and EEA1 colocalization was performed as follows. After internalization assays in 7-14 DIV hippocampal neurons, images were thresholded (generally at a level within fourfold to sixfold over background levels), and regions around EEA1 puncta were drawn and overlayed onto the channel showing internalized receptors. If the average intensity of an internalized NMDAR puncta residing within an EEA1-positive region was greater than the threshold value previously determined for a positive NMDAR puncta, the EEA1 region was considered positive for colocalization with NMDARs.

For quantification of internalization of Tac chimeras and mutants, cells were: (1) incubated at $4^{\circ} \mathrm{C}$ for $15 \mathrm{~min}$ and then acid stripped for 5 min at $4^{\circ} \mathrm{C}$ (background), (2) incubated at $37^{\circ} \mathrm{C}$ for $15 \mathrm{~min}$ and acid stripped for $5 \mathrm{~min}$ at $4^{\circ} \mathrm{C}$ (internalized receptors), or (3) incubated at $4^{\circ} \mathrm{C}$ for $15 \mathrm{~min}$ and then incubated in PBS for $5 \mathrm{~min}$ at $4^{\circ} \mathrm{C}$ (total surface expression) before fixation, permeabilization, and incubation with a secondary antibody. Total fluorescence of 20-30 cells per condition was then determined on maximum confocal projections and averaged. The percentage internalized was determined by subtracting the average background intensity from the average intensity of internalized receptors and then dividing by the average surface intensity.

Quantitative immunoblot analysis. Cell lysates from COS7 cells expressing Tac or Tac-C0 were performed as described previously (Scott et al., 2003), except that before harvesting the cells, $20 \mu \mathrm{g} / \mathrm{ml}$ of the protein synthesis inhibitor cycloheximide (Sigma) was added for the times indicated. Total protein $(25 \mu \mathrm{g})$ was then separated by SDS-PAGE, probed with anti-Tac antibody $(1: 1000)$, and band intensities were visualized and quantified using a PhosphorImager (Molecular Dynamics, Sunnyvale, $C A$ ). Band intensities from each time point were then normalized to the $t=0$ signal, and the average ratio was plotted.

Electrophysiology. Xenopus laevis (African clawed frog) oocytes of stage $\mathrm{V}$ and VI were surgically removed from ovaries and digested with collagenase using standard methods. Oocytes were kept in OR2 (supplied with $\mathrm{Ca}^{2+}$ ) containing (in mM): $82.5 \mathrm{NaCl}, 2 \mathrm{KCl}, 1 \mathrm{MgCl}_{2}, 5 \mathrm{HEPES}$, $\mathrm{pH} 7.5$, and $1.8 \mathrm{CaCl}_{2}$ for $1-3 \mathrm{~d}$. For electrophysiological recordings, cRNAs were introduced in oocytes by microinjection $(50 \mathrm{nl}$ per oocyte) with a 1:1 subunit ratio. Recordings were performed $1-2 \mathrm{~d}$ after injection using a Dagan (Minneapolis, MN) two-electrode voltage-clamp amplifier, and currents were obtained with a square pulse protocol. Bath solution (Ringer's) contained the following (in mM): $115 \mathrm{NaCl}, 2.5$ $\mathrm{KCl}, 1.8 \mathrm{BaCl}_{2}$, and 10 HEPES, $\mathrm{pH}$ 7.2. Rapid solution exchange was achieved with a gravity flow perfusion system converging on a $6 \mu$ loocyte chamber engineered in our laboratory from inert materials.

After the establishment of a baseline, NMDA $(100 \mu \mathrm{M})$ and glycine (10 $\mu \mathrm{M}$ ) were added, and NMDAR whole-cell currents were measured. For all cells, baseline currents were obtained for $10 \mathrm{sec}$ before application of agonist for at least 22-24 sec. Steady-state current measurements consisted of the average of the baseline current subtracted from the average current between 13 and $17 \mathrm{sec}$ after agonist application.

(Figure legend continued.) white box. Scale bars: top panels, $10 \mu \mathrm{m}$; bottom panels, $5 \mu \mathrm{m}$. E, Deletion of the C 0 domain of NR1 increases whole-cell NMDA-evoked currents. Wild-type NR1 subunits or mutant subunits lacking the CO domain (amino acids $838-863 ; N R 1 \Delta(0)$ were expressed in Xenopus 0ocytes together with NR2A-stop850, a mutant NR2A subunit containing a stop codon at residue 850 . Whole-cell currents were recorded at $-80 \mathrm{mV}$ using two-electrode voltage clamp. Representative traces from cells expressing NR1/NR2A-stop850 (left) or NR1 $\Delta$ C0/NR2A-stop850 (right) are shown. After the establishment of a baseline, cells were perfused with NMDA $(100 \mu \mathrm{M})$ and glycine $(10 \mu \mathrm{M})$ as indicated by the calibration bar. $F$, Quantification of whole-cell NMDA-evoked currents from $E$. Data represents means \pm SEM; ${ }^{*} p<0.05 ; t$ test. C, C terminus; $N, N$ terminus; IL2 $\alpha$, interleukin-2 receptor $\alpha$ subunit.

\section{Results \\ The C-terminal intracellular domain of NR1 mediates endocytosis}

NR2 subunits contain signals that regulate the insertion and internalization of NMDARs at synaptic sites (Roche et al., 
2001; Barria and Malinow, 2002; Carroll and Zukin, 2002; Wenthold et al., 2003). To determine whether NR1 subunits contribute to NMDAR internalization, we coexpressed full-length NR1 containing an N-terminal YFP tag (YFP-NR1) along with myc-tagged NR2B (NR2B) or myctagged NR2B lacking its intracellular C-terminal domain (NR2B- $\Delta \mathrm{C}$ ) (Fig. $1 \mathrm{~A})$. Surface staining at $4^{\circ} \mathrm{C}$ using an antiGFP antibody on COS7 cells coexpressing either YFP-NR1-1a/NR2B or YFP-NR1$1 \mathrm{a} / \mathrm{NR} 2 \mathrm{~B}-\Delta \mathrm{C}$ revealed that both wild-type and mutant NMDAR complexes, the latter lacking the large intracellular tail of NR2B subunits, were robustly expressed at the plasma membrane (Fig. $1 B$, left). After incubation at $37^{\circ} \mathrm{C}$, live-labeled NR1-1a/NR2B complexes concentrated in intracellular puncta indicative of internalized receptors (Fig. $1 B$, right). Surprisingly, the internalization of live-labeled receptors was observed regardless of whether YFP-NR1-1a subunits were coexpressed with wild-type NR2B or mutant NR2B- $\Delta$ C lacking all known NMDAR endocytic signals (Fig. $1 B$, right). Importantly, internalized receptors represent assembled NR1/NR2 heteromers, because unassembled YFP-NR1-1a by itself is unable to reach the plasma membrane (Okabe et al., 1999; Standley et al., 2000; Scott et al., 2001; Xia et al., 2001). For all remaining experiments, we used YFPNR1-4a (YFP-NR1), a splice variant of NR1 that is more efficiently expressed at the cell surface (Okabe et al., 1999; Barria and Malinow, 2002) (data not shown), which in turn greatly increased our ability to detect and measure endocytosis by surface labeling. Relative to YFP-NR1-1a, we observed no qualitative difference in the internalization of YFP-NR1-4acontaining NMDARs (Fig. $1 B, C$ ). Moreover, both wild-type and mutant mycNR2B subunits always colocalized with internalized YFP-NR1-4a (YFP-NR1) receptors in intracellular vesicles (Fig. 1C), supporting endocytosis of assembled NR1/NR2 heteromers.

To determine whether NR1 subunits drive NMDAR endocytosis in neuronal dendrites, we expressed YFP-NR1/NR2B or YFP-NR1/NR2B- $\Delta \mathrm{C}$ in hippocampal neurons and performed endocytosis assays. When maintained at $4^{\circ} \mathrm{C}$, surfacelabeled YFP-NR1/NR2B remained at the cell surface and showed minimal internalization or transport to early endosomes as revealed by double labeling for the early endosomes marker EEA1 (Fig. 1D,E) $(8.9 \pm 3.4 \%$ early endosomes contained live-labeled receptors; 728 endosomes
A

\section{EIAYKRHKDARRKQMQLAFAAVNVWRKNLQ}
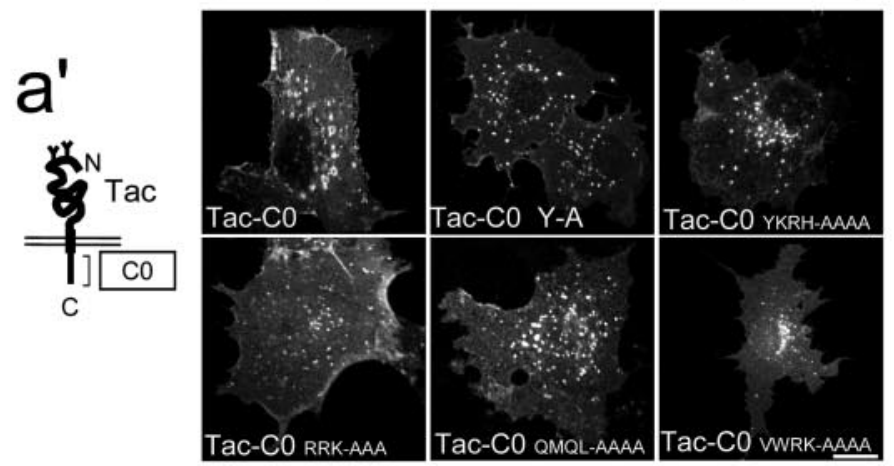

D
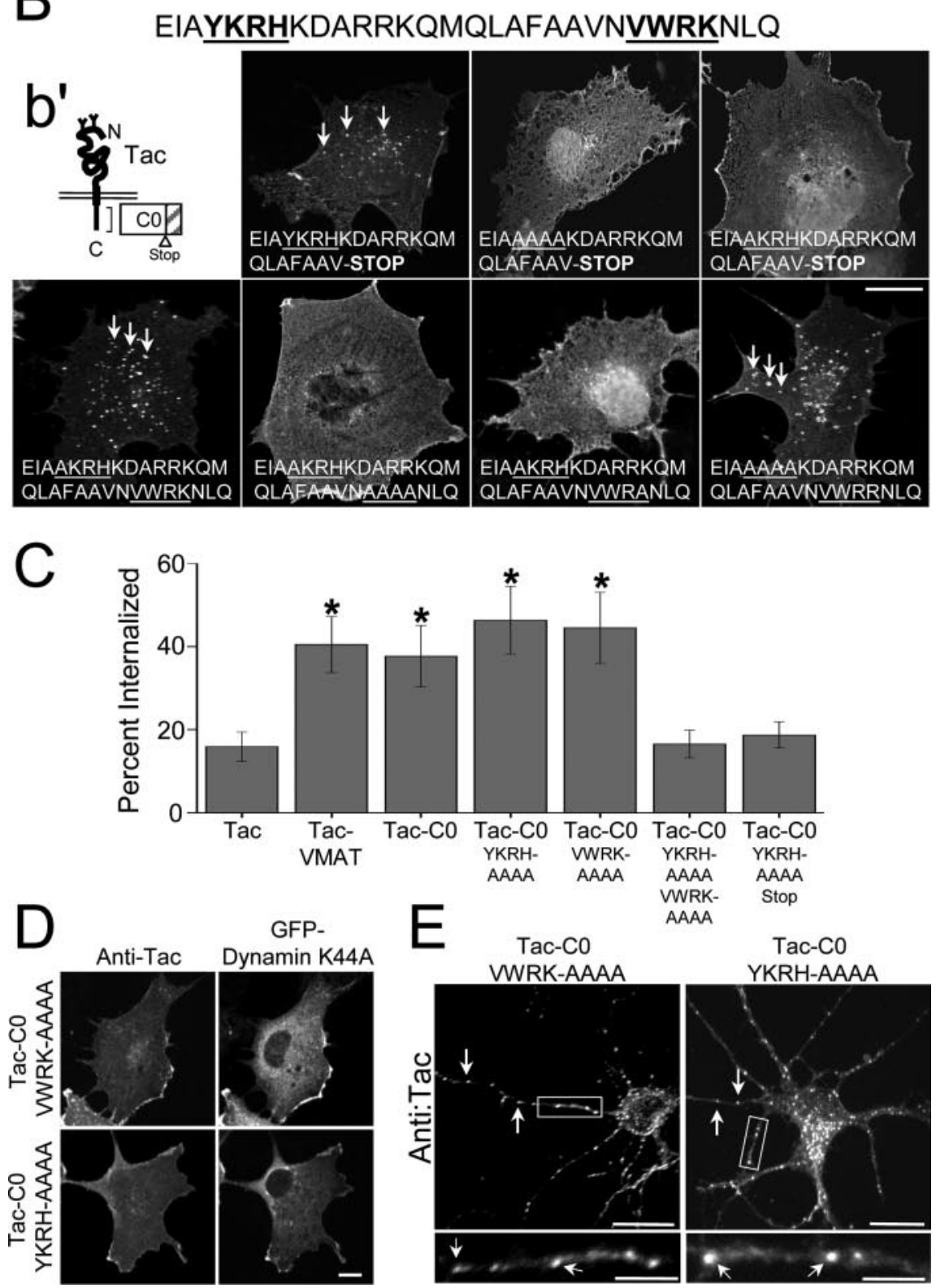

Tac-C0

YKRH-AAAA

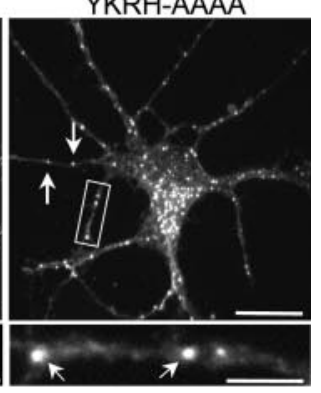

Figure 3. The CO domain of NR1 contains two independent endocytic motifs. A, Internalization of Tac-CO point mutants in COS7 cells. After 30 min internalization assays, Tac-CO receptors containing individual mutations in putative endocytic motifs were still internalized. The sequence of the $C 0$ domain is shown (top) as well as a schematic representation of Tac-CO receptors ( $a$ ). The two endocytic motifs identified in later experiments are underlined. Scale bar, $10 \mu \mathrm{m} . B$, Truncated (Figure legend continues.) 
from 5 neurons). However, after incubation at $37^{\circ} \mathrm{C}$ for $15 \mathrm{~min}$, surface-labeled NR1/NR2B was rapidly internalized and transported to EEA1-postive early endosomes (Fig. 1D,E) $(48 \pm 11 \%$ early endosomes contained live-labeled receptors; 642 endosomes from 5 neurons; $p<0.05$ vs YFP-NR1/NR2B incubated at $4^{\circ} \mathrm{C}$ ). As in COS7 cells (Fig. $1 B, C$ ), NMDARs lacking NR2 C-terminal domains (YFP-NR1/NR2B- $\Delta$ C) also underwent robust internalization and transport to early endosomes (Fig. $1 D, E)(34 \pm 6.5 \%$ early endosomes contained live-labeled receptors; 786 endosomes from 7 neurons; $p<0.05$ vs YFP-NR1/ $\mathrm{NR} 2 \mathrm{~B}$ incubated at $4^{\circ} \mathrm{C}$ ). Together, these data show that NMDARs undergo rapid internalization in the absence of intracellular endocytic signals within the large C-terminal domain of NR2 (Roche et al., 2001), suggesting the presence of alternate signals within NR1 subunits that mediate endocytosis.

\section{The C0 domain of NR1 is sufficient to drive receptor internalization}

Four different C-terminal NR1 splice variants exist (Zukin and Bennett, 1995) (Fig. 2A), which contain a unique set of forward trafficking signals (Standley et al., 2000; Scott et al., 2001; Xia et al., 2001; Mu et al., 2003), but the role of NR1C-terminal signals in membrane stabilization or endocytosis has not been examined. To determine whether NR1 C-terminal domains mediate endocytosis, weperformed internalization assays on COS7 cells expressing chimeric receptor molecules composed of the human interleukin-2 receptor $\alpha$ subunit (Tac), to which portions of the intracellular $\mathrm{C}$ terminus of NR1 was appended (Fig. 2A). Live surface labeling of COS7 cells expressing Tac, Tac-C2, or Tac-C2' revealed a uniform plasma membrane distribution that was unchanged by incubation for $30 \mathrm{~min}$ at $37^{\circ} \mathrm{C}$ (conditions that allow for endocytosis) (Fig. $2 \mathrm{~B}$ ). In contrast, surface labeling of Tac-C0 followed by $37^{\circ} \mathrm{C}$ incubation for $30 \mathrm{~min}$ revealed robust internalization and translocation into punctate endocytic vesicles (Fig. $2 B)$. The vesicular distribution of Tac-C0 was similar to that of Tac-VMAT, a Tac chimeric receptor containing a wellcharacterized endocytic motif of the vesicular monoamine transporter (Tan et al., 1998) (Fig. 2B), and was also similar to the distribution of full-length NMDARs after internalization assays in COS7 cells (Fig. $1 B, C$ ). Moreover, internalization of Tac-C0 was prevented when cells were kept at $4^{\circ} \mathrm{C}$ (Fig. $2 \mathrm{~B}$ ) and was completely blocked in cells expressing a dominant-negative form of the large GTPase dynamin (dynamin-K44A) (Fig. 2C). In addition, Tac-C0 present in punctate vesicles after $37^{\circ} \mathrm{C}$ incubation was unaffected by acid stripping of remaining surface bound an-

\footnotetext{
$\leftarrow$

(Figurelegend continued.) TAC-CO receptors containing only the first 22 amino acids of the CO domain undergo robust endocytosis (top left panel, arrows), which is abolished by mutations of Y838 (Y838A) (top right panel). Because the Y838A mutation did not block internalization of Tac-CO receptors (bottom left panel, arrows), another endocytic signal must be present. This signal resides within VWRK, because Tac-CO receptors containing point mutations in both Y838 (Y838A) and VWRK (VWRK-AAAA) were unable to be internalized from the plasma membrane (bottom row, second panel). Within the VWRK sequence, K861 was necessary to drive the internalization of mutant Tac-CO receptors that lacked the Y838 endocytic signal (bottom row, third panel). However, K861 is not a site of ubiquitination, because Tac-C0 K861R mutants were still internalized (bottom right panel, arrows). A schematic representation of mutant Tac-CO receptors is shown (b) as well as the sequence of the CO domain (top). Scale bar, $10 \mu \mathrm{m}$. C, Quantification of Tac internalization. Data represent means $\pm S E M$ of the percentage of receptors internalized in $15 \mathrm{~min}$ (see Materials and Methods). ${ }^{*} p<0.05$ relative to Tac; $t$ test. $D, Y K R H$ and VWRK endocytic signals are dynamin dependent. Internalization assays were performed on COS7 cells coexpressing Tac-CO mutants (Tac-CO-VWRK-AAAA or Tac-CO-YKRH-AAAA) and GFP-tagged dominant-negative dynamin (K44A). In cells expressing dynamin-K44A (right panels), endocytosis was abolished, and Tac receptors remained at the plasma membrane (left panels; compare with A). Scale bar, $10 \mu \mathrm{m}$. E, Both YKRH and VWRK motifs drive the internalization of Tac receptors in neurons. Internalization assays were performed on hippocampal neurons (10 DIV) expressing either Tac-CO-VWRK-AAAA or Tac-CO-YKRH-AAAA. Arrows designate internalized Tac-CO receptors. Boxed regions are magnified in corresponding bottom panels. Scale bars, $20 \mu \mathrm{m}$; magnified dendrite regions, $5 \mu \mathrm{m}$. $\mathrm{C}, \mathrm{C}$ terminus; N, N terminus.
}

tibodies, whereas Tac, Tac-C2, and Tac-C2' labeling was completely removed by acid stripping (data not shown), further establishing the selective endocytosis of Tac-C0. Importantly, the $\mathrm{CO}$ domain of NR1 was also sufficient to drive internalization of sured whole-cell NMDA-evoked currents in Xenopus expressing wild-type or mutant NMDAR complexes that lacked the C0 domain of NR1 (NR1- $\Delta \mathrm{C} 0)$. To eliminate any potential taining a stop codon at residue 850 that lacks nearly the entire C-terminal domain (NR2A-stop 850). For these experiments, NR2A-stop850 was used instead of C-terminal deletions of NR2B occause of its more robust and consistent expression in Xenopus tions). Deletion of the $\mathrm{C} 0$ domain of $\mathrm{NR} 1$ caused a marked increase in whole-cell NMDA currents (NR1- $\Delta$ C0/NR2A-stop 850, $2.96 \pm 0.55 \mu \mathrm{A} ; n=24$ oocytes from 2 animals; $p<0.05)$ com22 oocytes from 2 animals) (Fig. $2 E, F)$. Notably, these $n$ ments were performed in the absence of extracellular $\mathrm{Ca}^{2+}$ to prevent any $\mathrm{C} 0$-dependent changes in single-channel properties (Legendre et al., 1993; Ehlers et al., 1996; Zhang et al., 1998; Krupp et al., 1999). Thus, the dramatic increase in NMDAceptor surface expression and is consistent with our findings that the C0 domain mediates endocytosis (Fig. $2 B, C$ ). Together, these results demonstrate that the C0 domain of NR1 contains a dynamin-dependent endocytic motif that functions in both hippocampal neurons and non-neuronal cells to regulate the func-

\section{Two distinct endocytic motifs reside within the $\mathrm{C} 0$ domain} To identify the specific amino acid sequences within the $\mathrm{C} 0$ domain that mediate endocytosis, we generated mutations within $\mathrm{CO}$ and determined the effect of these mutations on the internalization of Tac-C0. Surprisingly, disruption of several residues (Y838) use-dependent downregulation of NMDARs (Vissel et al., , did not block the internalization of Tac-C0 (Fig. 3A). In fact, no single-point mutation or mutation of three to four adjacent amino acids affected endocytosis mediated by the $\mathrm{C} 0$ domain (Fig. 3A) (data not shown). As such, we hypothesized that the CO domain contains multiple signals sufficient to drive the internalization of NR1 subunits. To examine this possibility, internalization assays were performed on COS7 cells expressing complex Tac-C0 mutants that contained several point mutations and/or early truncations. As shown in Figure 3B, the first 22 amino acids of the $\mathrm{C} 0$ domain were sufficient to drive the internalization of chimeric receptors (Fig. $3 B$, top left panel). In the context of this shortened Tac-C0, Y838 was absolutely required for internalization (Fig. 3B, top panels). Furthermore, addition of the final eight amino acids of C0 (NVWRKNLQ) 
restored endocytosis of Tac-C0-Y838A, revealing a second endocytic determinant (Fig. 3B, bottom left panel). Endocytosis mediated by this second determinant was abolished by mutations of the VWRK amino acid sequence, and within this motif, K861 was required for internalization (Fig. $3 B$, middle two panels in bottom row). Thus, only when both the YKRH (Y838) and VWRK (K861) signals were mutated was the internalization of Tac-C0 receptors abolished (Fig. $3 B$ ). The requirement for a lysine residue, K861, raised the possibility that ubiquitination at this residue was required for NR1 endocytosis (Hicke and Dunn, 2003). However, mutation of lysine 861 to arginine (K861R) had no effect on endocytosis mediated by the VWRK signal (Fig. 3B, bottom right panel), suggesting that positive charge at this site rather than covalent modification by ubiquitin was required for endocytosis. Together, these results indicate that both tyrosine-based (YKRH) and lysine-based (VWRK) endocytic signals within the C0 domain of NR1 independently drive internalization.

To determine the relative contribution of YKRH and VWRK motifs to C0-mediated endocytosis, we measured the internalization of wild-type and mutant Tac chimeric receptors using quantitative immunofluorescence. As illustrated in Figure $3 C$, the $\mathrm{C} 0$ domain increased the internalization of Tac receptors approximately twofold $(37.6 \pm 7.3 \%$ surface-labeled Tac internalized; $n=5 ; p<0.05)$ when compared with Tac alone $(15.9 \pm 3.5 \%$; $n=5)$. This $\mathrm{C} 0$-dependent increase in internalization was quantitatively similar to the observed internalization of Tac-VMAT (40.5 $\pm 6.7 \% ; n=3 ; p<0.05$ compared with Tac) (Fig. $3 C$ ). Disruption of either YKRH (Tac-CO YKRH-AAAA) or VWRK (Tac-C0 VWRK-AAAA) alone did not block or reduce the internalization of chimeric receptors (Tac-C0 YKRH-AAAA, $46.3 \pm$ $8.1 \%, n=5, p<0.05$ compared with Tac; Tac-C0 VWRK-AAAA, $44.5 \pm 8.5 \%, n=7, p<0.05$ compared with Tac), indicating that each endocytic motif is capable of driving internalization of receptors to a degree similar to that of wild-type Tac-C0 receptors (Fig. 3C). Only when both YKRH and VWRK motifs were mutated was internalization abolished (Tac-C0 YKRH-AAAA VWRK-AAAA, $18.7 \pm 3.1 \%, n=4$; Tac-C0 YKRH-AAAA Stop, $16.6 \pm 3.3 \%, n=4)$. This all or none effect of mutations in the YKRH and VWRK motifs demonstrated that these two endocytic signals are not additive but rather independently mediate endocytosis to an extent identical to intact C0.

Consistent with dual and perhaps redundant function of the VWRK and YKRH endocytic motifs, we found that the internalization of both Tac-CO-VWRK-AAAA and Tac-C0-YKRHAAAA was dynamin dependent, because it was blocked by overexpression of dominant-negative dynamin-K44A (Fig. 3D). Furthermore, the VWRK and YKRH motifs were each sufficient to drive endocytosis of $\mathrm{C} 0$-containing receptors in hippocampal neurons (Fig. 3E). These data further support our conclusion that the C0 domain of NR1 contains two independent endocytic motifs.

\section{C-terminal domains of NR1 and NR2B contribute independently to NMDAR endocytosis}

Subunit composition controls NMDAR synaptic localization (Mori et al., 1998; Steigerwald et al., 2000; Prybylowski et al., 2002) and synaptic stability (Barria and Malinow, 2002). However, the relative contribution of NR1 and NR2 subunits to receptor endocytosis remains unknown. To determine the role of C-terminal domains of NR1 and NR2 in NMDAR internalization, we monitored the endocytosis of heteromeric NR1-NR2B complexes in hippocampal neurons (10-14 DIV) using live cell antibody-feeding assays. We chose NR2B because this NR2 subunit has been found previously to contain an endocytic motif
(Roche et al., 2001; Lavezzari et al., 2003). When expressed in hippocampal neurons, YFP-NR1/NR2B complexes readily reached the plasma membrane and underwent robust endocytosis $\left(15 \mathrm{~min}, 37^{\circ} \mathrm{C}\right)$ (Fig. $\left.4 A, B\right)$. Interestingly, NR1/NR2 receptors in which either the entire NR2B C-terminal domain was deleted (NR2B- $\Delta \mathrm{C}$ ) or both endocytic motifs were mutated in the C0 domain of NR1 (YFP-NR1-YK838-9AA, VWRK858861AAAA; termed NR1-Mut) were likewise endocytosed in hippocampal neurons (Fig. $4 A$ ) but to a lesser extent than wild-type receptors (Fig. $4 B$ ). That is, the endocytosis of YFP-NR1/ NR2B- $\Delta$ C and YFP-NR1-Mut/NR2B was significantly reduced compared with wild-type NR1/NR2B (Fig. 4 B) (internalized/surface ratios normalized to YFP-NR1/NR2B: YFP-NR1/NR2B- $\Delta$ C, $0.58 \pm 0.15, n=11, p<0.05$; YFP-NR1-Mut/NR2B, $0.62 \pm 0.06$, $n=15, p<0.01)$. In contrast, endocytosis was nearly completely abolished in NMDARs lacking both the C-terminal tail of NR2B and the endocytic motifs within the C0 domain of NR1 (internalized/surface ratio normalized to YFP-NR1/NR2B: YFP-NR1Mut/NR2B- $\Delta$ C, $0.28 \pm 0.11, n=9, p<0.05$ compared with wild-type YFP-NR1/NR2B and YFP-NR1-Mut/NR2B). The remaining signal in the endocytosis assays of YFP-NR1-Mut/ NR2B- $\Delta$ C receptors was at background levels because it was indistinguishable from that obtained from wild-type NR1/NR2B receptors, in which endocytosis assays were performed at $4^{\circ} \mathrm{C}$ $\left(0.20 \pm 0.10\right.$ normalized to YFP-NR1/NR2B at $\left.37^{\circ} \mathrm{C} ; n=6\right)$ (Fig. $4 B)$, conditions that prevent internalization. Importantly, NR1Mut and NR2B- $\Delta$ C were able to coassemble with each other and corresponding wild-type subunits (data not shown), and under our experimental conditions of excess NR2B, surface-expressed NR1 subunits are fully assembled with NR2B subunits (McIlhinney et al., 1998; Okabe et al., 1999; Scott et al., 2001).

To further confirm that the endocytic signals in the membrane-proximal C0 domain of NR1 contribute to NMDAR endocytosis, we performed antibody labeling internalization assays on hippocampal neurons and monitored the transport of internalized receptors into early endosomes. Consistent with a decrease in basal endocytosis, NMDARs lacking C0 endocytic signals (YFP-NR1-Mut/NR2B) exhibited significantly less transport into early endosomes labeled with the early endosome marker EEA1 when compared with wild-type NR1/NR2B receptors (Fig. 4C,D) (YFP-NR1-Mut/NR2B, $22 \pm 3.8 \%$ early endosomes contained live-labeled receptors after $15 \mathrm{~min}$ at $37^{\circ} \mathrm{C}, 872$ endosomes from 7 neurons; YFP-NR1/NR2B, $48 \pm 11 \%, p<$ $0.05)$. Although quantitatively less than wild-type receptors, NMDARs lacking C0 endocytic motifs were still transported to early endosomes (Fig. 4C,D), consistent with the observed partial reduction in basal endocytosis (Fig. $4 B$ ). Together, these findings demonstrate that endocytic motifs in the membrane-proximal C0 domain of NR1 contribute to internalization of full-length NMDARs in hippocampal neurons. Moreover, these results indicate that C-terminal domains of NR1 and NR2B contribute in an additive manner to NMDAR endocytosis. Finally, these data show that endocytic signals in NR1 and NR2B mediate transport into early endosomes in the initial phase of postendocytic trafficking.

\section{The NR2B C-terminal domain promotes recycling of internalized NMDARs}

After endocytosis and transport into early endosomes, internalized membrane proteins are sorted along two major intracellular pathways: a recycling pathway for reinsertion into the plasma membrane and a degradative pathway via late endosomes to lysosomes (Mellman, 1996; Mukherjee et al., 1997). For many in- 
A
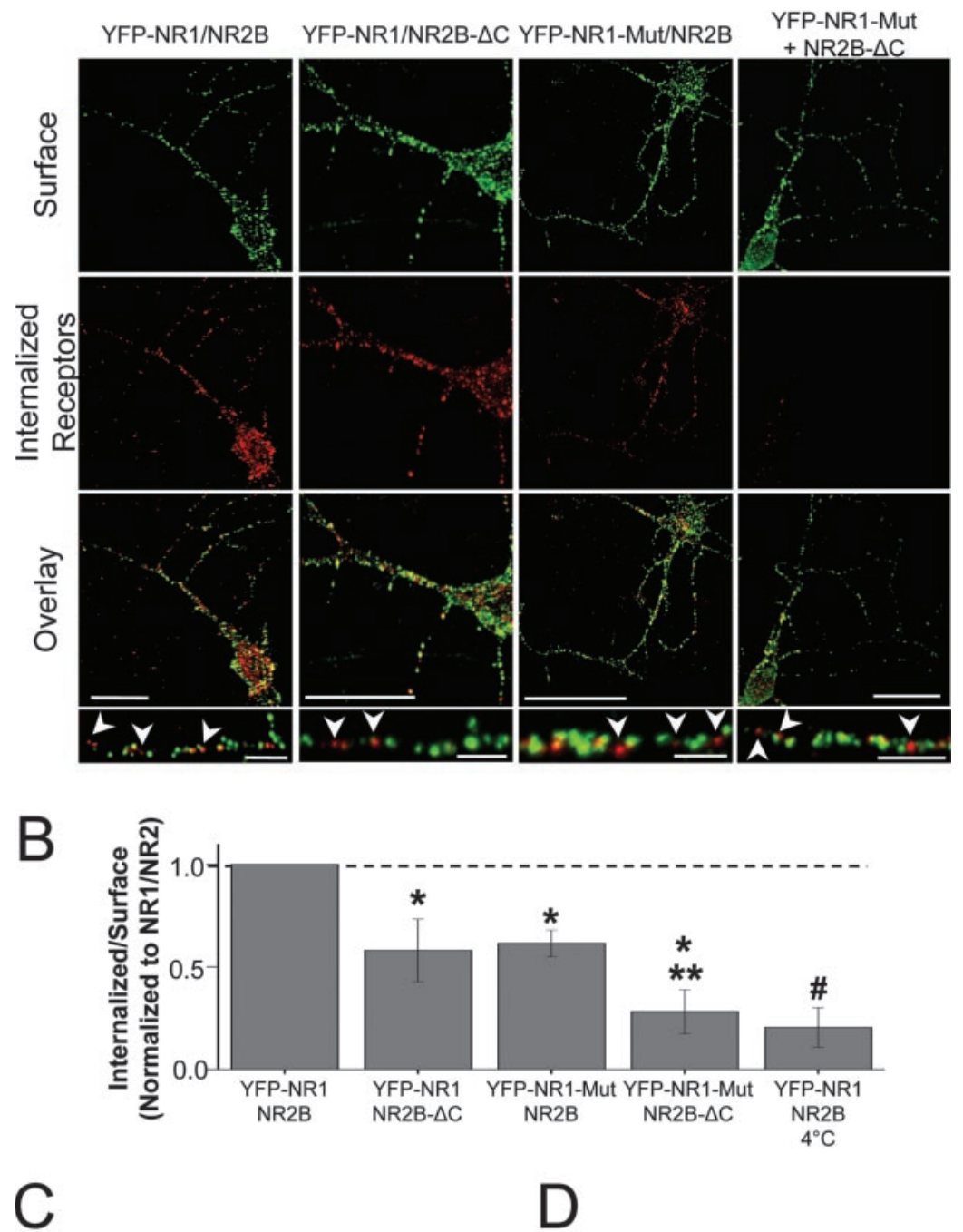
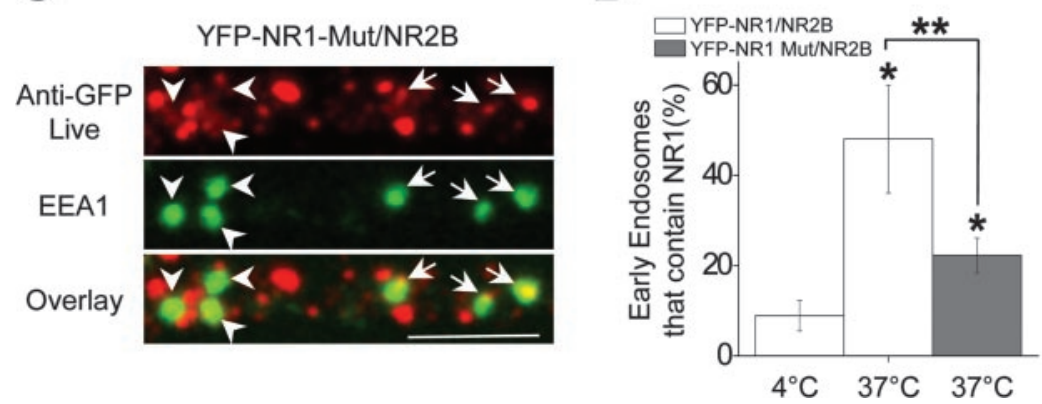

Figure 4. NR1 and NR2B subunits contribute additively to NMDAR endocytosis. A, Both NR1 membrane-proximal endocytic motifs and NR2B C-terminal domains are required for NMDAR internalization. Hippocampal neurons (10-14 DIV) coexpressing YFP-NR1/NR2B, YFP-NR1/NR2B- $\Delta$ C, mutant YFP-NR1-YK838-9AA, VWRK858-61AAAA (YFP-NR1-Mut)/NR2B, or YFP-NR1Mut/NR2B- $\Delta C$ were incubated live for $15 \mathrm{~min}$ at $37^{\circ} \mathrm{C}$ with an anti-GFP antibody before fixation and incubation with secondary antibody under nonpermeant conditions (surface, green). Internalized receptors were then detected by subsequent permeabilization and incubation with secondary antibody conjugated with a different fluorophore (red). Scale bars, $20 \mu \mathrm{m}$; insets, $5 \mu \mathrm{m}$. Arrowheads indicate internalized receptors. $B$, Quantification of wild-type and mutant NMDAR internalization in hippocampal neurons. Data represent means $\pm S E M$ of the relative proportion of internalized receptors to surface receptors from $A$ normalized to values obtained for wild-type YFP-NR1/NR2B. ${ }^{*} p<0.05$ relative to wild-type YFP-NR1/NR2B; ${ }^{* *} p<0.05$ relative to single mutants; ${ }^{\#} p<0.05$ relative to all subunit pairs except the double mutant (YFP-NR1-Mut/NR2B- $\Delta$ C). C, Hippocampal neurons (10-14 DIV) coexpressing YFP-NR1-Mut/NR2B were incubated live at $37^{\circ} \mathrm{C}$ for $15 \mathrm{~min}$ with anti-GFP antibody, fixed, permeabilized, and stained with an anti-EEA1 antibody to visualize early endosomes (green). Note that a subpopulation of YFP-NR1-Mut/ NR2B puncta colocalized with EEA1 (arrows), although many early endosomes lacked NMDAR labeling (arrowheads). Scale bar, 5 $\mu \mathrm{m} . D$, Data represent means \pm SEM of the percentage of EEA1-positive puncta that contain endocytosed NMDARs in hippocampal neurons. Note that NMDARs lacking NR1 endocytic motifs (YFP-NR1-Mut/NR2B) exhibited less colocalization with EEA1 than corresponding wild-type NMDARs. ${ }^{*} p<0.05$ relative to YFP-NR1/NR2B at $4^{\circ} \mathrm{C}$; ${ }^{* *} p<0.05$; $t$ test. tegral membrane proteins, including receptor tyrosine kinases, G-proteincoupled receptors, and AMPARs, this sorting decision is regulated by specific endocytic motifs or intracellular signals (Ehlers, 2000; Wiley and Burke, 2001; Bonifacino and Traub, 2003; von Zastrow et al., 2003). In the case of NMDARs, the fate of internalized receptors has been unclear. To address this question, we first tested whether internalized NMDARs return to the plasma membrane using antibody-based receptor recycling assays (see Materials and Methods for details). Hippocampal neurons expressing YFPNR1/NR2B were labeled live with antiGFP antibody and receptor-antibody complexes allowed to undergo endocytosis by shifting the temperature to $37^{\circ} \mathrm{C}$ for $30 \mathrm{~min}$. Remaining surface-bound antibodies were removed by acid stripping, and any residual unstripped antibody was blocked with an unconjugated secondary antibody. After a second period of $37^{\circ} \mathrm{C}$ incubation to allow recycling (60 $\mathrm{min}$ ), surface labeling of NMDARs revealed numerous punctate collections of recycled NMDARs (YFP-NR1/NR2B) (Fig. 5A). This recycling was abolished if neurons were kept at $4^{\circ} \mathrm{C}$ during the recycling period (Fig. $5 B$ ) (YFP-NR1/NR2B $37^{\circ} \mathrm{C}$, $0.16 \pm 0.04$, recycled/internalized ratio, $n=8$ neurons, $p<0.05$; compared with YFP-NR1/NR2B $4^{\circ} \mathrm{C}, 0.05 \pm 0.01 \mathrm{recy}-$ cled/internalized ratio, $n=6$ neurons).

In contrast to the robust recycling of wild-type receptors, NMDARs lacking the intracellular C-terminal domain of NR2B were almost completely unable to recycle back to the plasma membrane $(>80 \%$ reduction relative to YFP-NR1/NR2B; YFPNR1/NR2B- $\Delta$ C, $0.07 \pm 0.01 \mathrm{recycled} / \mathrm{in}-$ ternalized ratio, $n=10$ neurons; $p<0.05$ ) (Fig. 5A,B). This lack of recycling was not simply attributable to reduced endocytosis, because values measured were normalized to fluorescence intensity values of internalized NMDARs labeled simultaneously. In addition, we noted that recycled YFP-NR1/NR2B receptors appeared as discrete puncta over the soma and dendrites (Fig. 5A). Double labeling with antibodies against the presynaptic marker synapsin revealed that recycled NMDARs were localized opposite presynaptic terminals (Fig. $5 C)(73.3 \pm 3.3 \%$ of recycled YFP-NR1/NR2B receptors colocalized with synapsin, $n=155$ recycled puncta from 5 neurons, whereas $81.4 \pm 3.7 \%$ of live-labeled YFP-NR1/NR2B receptors colocalized with synapsin when maintained at $4^{\circ} \mathrm{C}, n=133$ live-labeled puncta from 3 
A

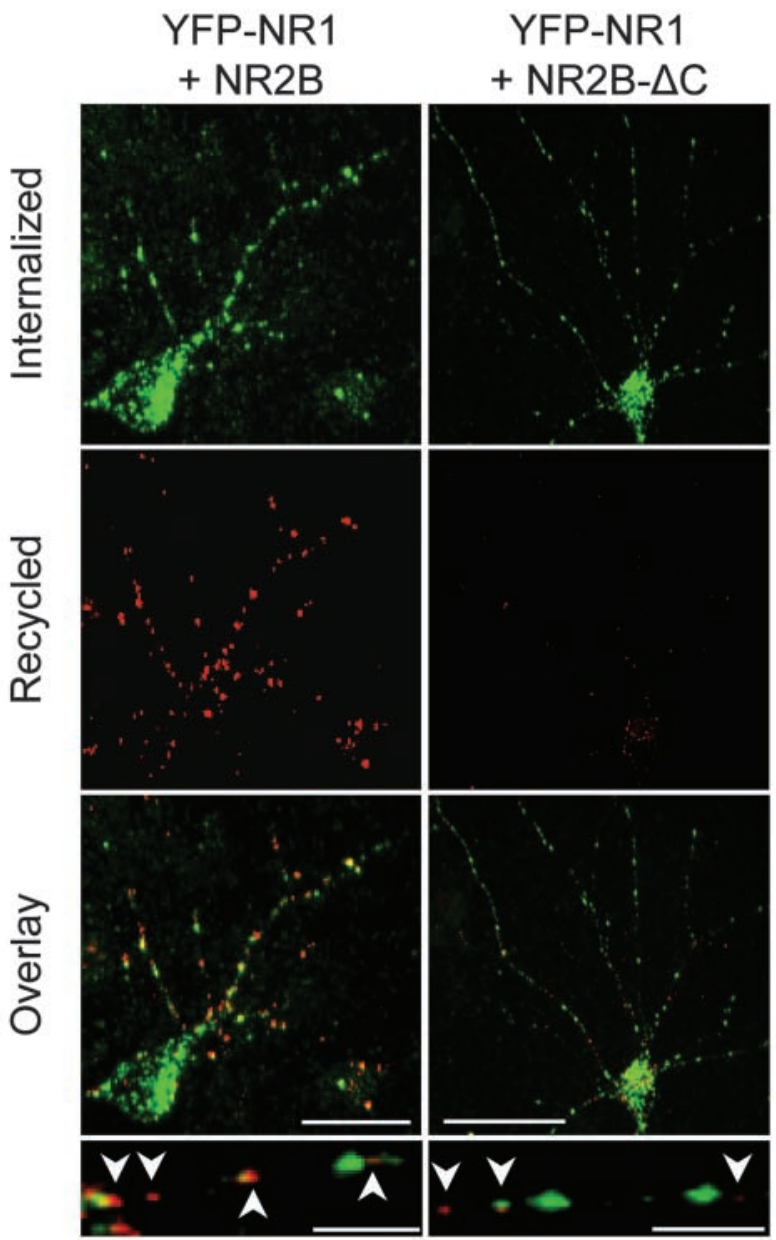

B
C

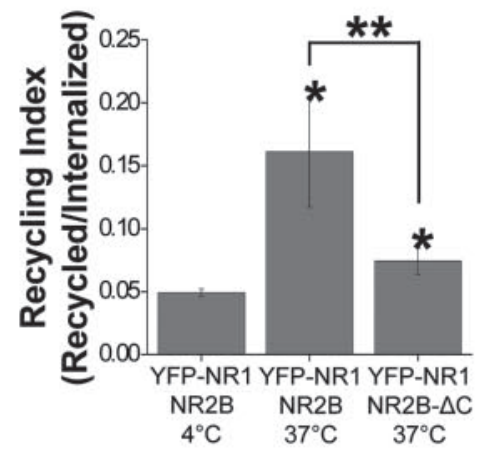

YFP-NR1/NR2B

Recycled

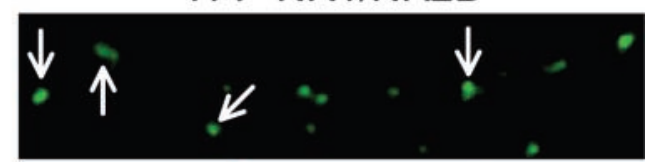

Synapsin

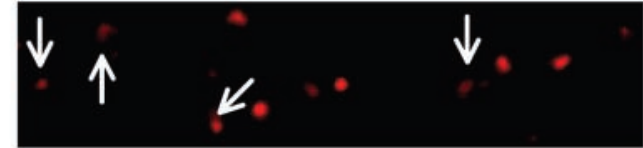

Overlay

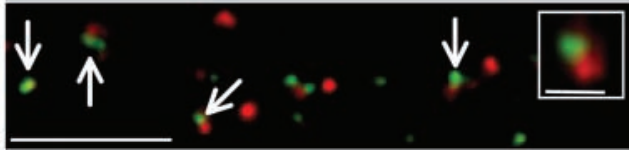

neurons; $p=0.16)$. Together with the above results, these findings demonstrate that NR1/NR2B receptors recycle back to the plasma membrane after endocytosis, and this recycling requires the C-terminal domain of NR2B. Moreover, these results indicate that endocytic signals present in NR1 are insufficient to target NMDARs to the recycling pathway. Finally, these data show that recycled NMDARs rapidly reaccumulate at synapses.

\section{NR1 membrane-proximal signals target receptors to late endosomes}

The lack of recycling of NR1/NR2B- $\Delta$ C receptors (Fig. 5), despite ample endocytosis (Fig. 1), suggested that endocytic signals within NR1 target receptors to nonrecycling pathways. Because the principal alternative to trafficking along recycling pathways is transport to late endosomes and lysosomes (Zerial and McBride, 2001; Maxfield and McGraw, 2004), we tested whether the C0 domain of NR1 directs cargo to the late endocytic pathway. Specifically, we followed the postendocytic trafficking of Tac-C0 in COS7 cells coexpressing GFP-Rab5 or GFP-Rab7, well-studied markers of early-sorting endosomes and late endosomes, respectively (Sonnichsen et al., 2000; Zerial and McBride, 2001). Within $15 \mathrm{~min}$, internalized Tac-C0 localized to intracellular endosomes and vesicles that colocalized with GFP-Rab5 (Fig. 6A, left panels), indicating initial transport into early endosomes. At later time points ( $60 \mathrm{~min}$ ), however, Tac-C0 failed to localize to transferrinpositive recycling compartments (Fig. 6A, middle panels) but rather localized to endosomes positive for GFP-Rab7 (Fig. 6A, right panels), a marker of late endosomes (Chavrier et al., 1990; Bucci et al., 2000; Zerial and McBride, 2001), indicating selective trafficking along the late endocytic pathway.

Trafficking of cargo to Rab7-positive late endosomes is often a precursor to lysosomal degradation (Meresse et al., 1995; Tjelle et al., 1996; Vitelli et al., 1997). To determine whether the C0 domain of NR1 accelerates protein degradation, we measured the rate of loss of Tac and Tac-C0 in COS7 cells treated with the protein synthesis inhibitor cycloheximide using quantitative immunoblot analysis. Treatment of COS7 cells expressing Tac with cycloheximide revealed a relatively slow rate of protein turnover $\left(t_{1 / 2}, \sim 3 \mathrm{hr}\right.$ ) (Fig. $\left.6 \mathrm{~B}, \mathrm{C}\right)$. In contrast, Tac receptors containing the $\mathrm{C} 0$ domain $(\mathrm{Tac}-\mathrm{C} 0)$ were much more rapidly degraded $\left(t_{1 / 2}\right.$, $\sim 1.6 \mathrm{hr}$ ) (Fig. $6 \mathrm{~B}, \mathrm{C}$ ). Thus, the $\mathrm{C} 0$ domain of NR1 selectively targets internalized receptors to late endosomes and accelerates

\section{$\leftarrow$}

Figure 5. The C-terminal domain of NR2B is required for NMDAR recycling. A, Hippocampal neurons (10 - 14 DIV) coexpressing YFP-NR1 and either wild-type NR2B (left) or NR2B lacking its C-terminal domain (NR2B- $\Delta$ C, right) were incubated live with anti-GFP antibody and receptorantibody complexes allowed to undergo endocytosis by shifting the temperature to $37^{\circ} \mathrm{C}$ for 30 min. Remaining surface-bound antibodies were removed by acid stripping and any residual unstripped antibody blocked with an unconjugated secondary antibody. Neurons were incubated at $37^{\circ} \mathrm{C}$ to allow recycling ( $60 \mathrm{~min}$ ), fixed, and recycled NMDARs labeled with fluorophoreconjugated secondary antibody under nonpermeant conditions (recycled, red). Internalized receptors were visualized by staining with a second fluorophore-conjugated secondary antibody after permeabilization (internalized, green). Scale bars, $20 \mu \mathrm{m}$; insets, $5 \mu \mathrm{m}$. Arrowheads indicate recycled receptors. $B$, Quantification of NMDAR recycling in hippocampal neurons. Data represent means \pm SEM of the recycled-internalized fluorescence intensity ratios. Four and $37^{\circ} \mathrm{C}$ designate the temperature neurons were incubated after the initial internalization of receptors. ${ }^{*} p<0.05$ relative to $4^{\circ} C ;{ }^{* *} p<0.05 ; t$ test. $C$, Recycled NMDARs reaccumulate at synapses. Recycling assays were performed as described in $A$ at $10-14$ DIV hippocampal neurons coexpressing YFP-NR1 and NR2B subunits (green) and costained with an anti-synapsin antibody (red) to visualize presynaptic terminals. Note that recycled NMDARs frequently localized near synaptic sites (arrows). Scale bars, $5 \mu \mathrm{m}$; inset, $1 \mu \mathrm{m}$. 


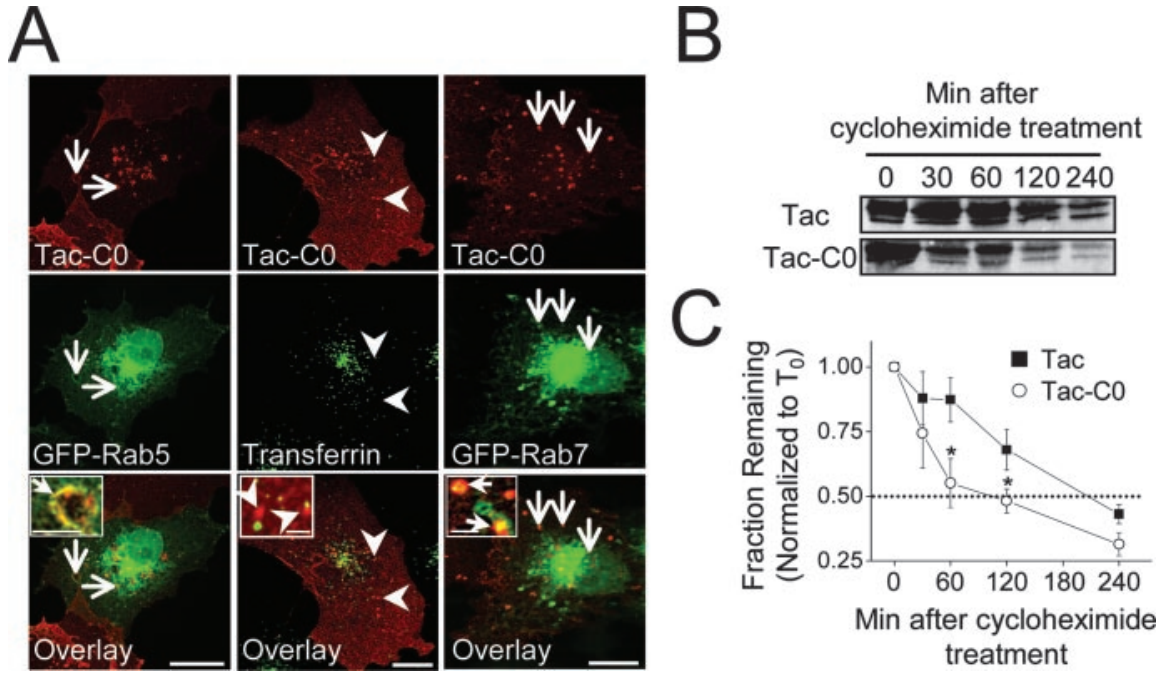

Figure 6. The CO domain of NR1 targets receptors to late endosomes and accelerates degradation. $A$, COS7 cells coexpressing Tac-C0 (red) and either GFP-Rab5 (green, left panels) or GFP-Rab7 (green, right panels) were surface labeled with anti-Tac antibody and incubated for $15 \mathrm{~min}$ (left panels) or $30 \mathrm{~min}$ (right panels) before fixation, permeabilization, and staining for internalized Tac. By 15 min, internalized Tac-C0 localized to Rab5-positive early endosomes (arrows, left panels). After 30-60 min, internalized Tac-CO did not colocalize with the recycling endosome marker Alexa-transferrin (arrowheads, middle panels) but rather appeared in Rab7-postive late endosomes (arrows, right panels). Scale bars, $10 \mu \mathrm{m}$; insets, $1 \mu \mathrm{m}$. B, The CO domain accelerates degradation of Tac. Immunoblots were performed on total protein ( $25 \mu \mathrm{g})$ from COS7 cells expressing Tac (top) or Tac-C0 (bottom) with anti-Tac antibody after treatment with the protein synthesis inhibitor cycloheximide (20 $\mu \mathrm{g} / \mathrm{ml})$ for the times indicated. The more rapid loss of Tac-CO indicates more rapid degradation. C, Quantitative analysis of blots shown in B. Data represent means $\pm S E M$ of band intensities normalized to the signal at time $0\left(T_{0}\right) .{ }^{*} p<0.05 ; t$ test; $n=3$.

protein degradation, revealing a differential role for NR1 and NR2B endocytic signals in intracellular sorting.

\section{A conserved family of membrane-proximal endocytic motifs in NMDARs}

The tyrosine-based endocytic motif in NR1 is similar to sequences in the corresponding region of NR2 subunits (Fig. 7A). To determine whether membrane-proximal domains of NR2 subunits are also capable of driving endocytosis, we constructed Tac-NR2 fusions containing the first 20 amino acids following the last transmembrane domain of NR2A (Tac-NR2A) or NR2B (Tac-NR2B) (Fig. 7A). Internalization assays on COS7 cells expressing Tac-NR2 revealed that the first 20 amino acids of NR2A and NR2B are sufficient to drive the internalization of chimeric receptors in both heterologous cells (Fig. $7 B$ ) and hippocampal neurons (Fig. 7C). Similar to $\mathrm{C} 0$, endocytosis mediated by membrane-proximal domains of NR2A and NR2B is dynamin dependent (Fig. 7D). In addition, as with the C0 domain of NR1 (Fig. 6), we observed that both Tac-NR2A and Tac-NR2B receptors trafficked to Rab5-positive early endosomes within $15 \mathrm{~min}$ (Fig. 7E,F), but after 30-60 min diverged from recycling cargo and appeared in Rab7-positive late endosomes (Fig. 7 E, F), demonstrating sorting to the late endocytic pathway. These findings demonstrate that juxtamembrane domains of both NR1 and NR2 subunits mediate endocytosis and target internalized receptors along a degradative pathway to late endosomes.

\section{Discussion}

In the present study, we demonstrated that the endocytosis and intracellular sorting of NMDARs are governed by an unexpected diversity of endocytic signals in NR1 and NR2 subunits. Membrane-proximal domains of NR1 and NR2 mediate internalization and transport along a degradative pathway to late en- dosomes. In contrast, distal C-terminal domains of NR2B mediate endocytosis and transport along a recycling pathway back to the plasma membrane. By alternately directing for degradation or recycling, endocytic motifs in the membraneproximal and distal $\mathrm{C}$ termini provide a powerful means to control NMDAR synaptic abundance by coordinating intracellular trafficking (Fig. 8).

\section{NMDAR endocytosis and} synapse modification

Endocytosis of NMDARs provides a cellular mechanism for regulating the number of NMDARs at excitatory synapses during synapse maturation and plasticity and may determine the propensity of synapses to undergo potentiation or depression, a process termed metaplasticity (Abraham and Bear, 1996). In response to low-frequency stimulation or activation of group I metabotropic glutamate receptors, CA1 hippocampal synapses undergo LTD (Bolshakov and Siegelbaum, 1994; Oliet et al., 1997) associated with the rapid loss of NMDARs from the postsynaptic membrane both in vitro (Snyder et al., 2001) and in vivo (Heynen et al., 2000). At CA3CA3 synapses, LTD is likewise accompanied by a marked reduction in NMDAR-mediated synaptic currents (Montgomery and Madison, 2002), suggesting regulated synaptic removal. Over somewhat longer periods, visual experience diminishes NMDAR-mediated transmission in visual cortical neurons, consistent with a reduction in the number of synaptic NMDARs (Philpot et al., 2001, 2003). Importantly, C-terminal regions of NR1 and NR2 play critical roles in receptor trafficking (Standley et al., 2000; Roche et al., 2001; Scott et al., 2001; Xia et al., 2001; Barria and Malinow, 2002; Carroll and Zukin, 2002; Prybylowski et al., 2002; Mu et al., 2003; Wenthold et al., 2003) and in the assembly of signaling complexes that trigger synaptic plasticity (Sprengel et al., 1998; Westphal et al., 1999; Bayer et al., 2001; Leonard et al., 2002; Kohr et al., 2003; Krapivinsky et al., 2003). Here, we have shown that NMDAR endocytosis is governed by endocytic signals in the membrane-proximal C-terminal domains of NR1 and NR2 subunits and the distal C-terminal region of NR2B. These spatially segregated endocytic signals act in an additive manner to drive NMDAR endocytosis and very likely respond to different intracellular signals. By regulating the speed, extent, or timing of NMDAR internalization, this diversity of endocytic motifs can ensure precise tuning of NMDAR surface levels and thus the magnitude of NMDAR-mediated $\mathrm{Ca}^{2+}$ influx.

\section{Role of membrane-proximal domains in use-dependent downregulation}

In response to strong or repeated agonist exposure, NMDARs undergo a progressive long-lasting decline in peak currents (Rosenmund and Westbrook, 1993a,b; Wang et al., 1993; Vissel et al., 2001; Li et al., 2002) that occurs independent of ion flux (Vissel et al., 2001). Interestingly, this use-dependent downregulation of NMDAR currents requires membrane-proximal domains of NR1 and NR2 subunits (Vissel et al., 2001) and is asso- 
ciated with a profound loss of NMDARs from the neuronal plasma membrane ( $\mathrm{Li}$ et al., 2002; Nong et al., 2003). Here, we have shown that membrane proximal domains of both NR1 and NR2 are primary signals for NMDAR endocytosis, which together form an "endocytic ring" near the intracellular mouth of the NMDA channel. These same domains direct internalized receptors along a degradative pathway to late endosomes. By accelerating receptor degradation, membrane proximal endocytic motifs are well positioned to mediate the long-lasting decrease in NMDAR activity associated with usedependent rundown after strong agonist activation (Rosenmund and Westbrook, 1993a,b). In addition, results provided here show that both the glycine-binding NR1 subunit and the glutamate-binding NR2 subunits each contain membrane proximal endocytic signals, providing an attractive explanation for the cooperative requirement of both coagonists in agonist-induced internalization (Nong et al., 2003). Finally, the positioning of membrane-proximal domains near the intracellular mouth of the NMDA channel places these endocytic motifs in a location amenable to sensing conformational changes during ligand binding or channel gating. Indeed, ligand binding increases the physical association of NMDARs with AP-2 adaptors (Nong et al., 2003), perhaps by conformation-dependent exposure of membrane-proximal endocytic motifs. Thus, membrane-proximal endocytic motifs are well suited to link channel conformation and gating to endocytosis and intracellular trafficking.

\section{Membrane-proximal C-terminal domains as central sites of NMDAR regulation}

Among the entire diversity of NMDAR heteromeric combinations, the 30 amino acid $\mathrm{C} 0$ domain of NR1 is the only C-terminal region present in all NMDARs. Consistent with this unique conservation, the $\mathrm{C} 0$ domain plays a critical role in coordinating $\mathrm{Ca}^{2+}$ signaling, cytoskeletal association, and channel function. Specifically, $\mathrm{Ca}^{2+}$ dependent inactivation of NMDARs requires binding of $\mathrm{Ca}^{2+}$-calmodulin to the C0 domain (Ehlers et al., 1996) that displaces the actin-binding protein $\alpha$-actinin 2 (Wyszynski et al., 1997; Zhang et al., 1998; Krupp et al., 1999) and in turn results in a decrease in mean channel open time and open probability (Ehlers et al., 1996). In addition, the $\mathrm{C} 0$ domain serves as a docking site for activated CaMKII $\left(\mathrm{Ca}^{2+}-\right.$ calmodulin-dependent protein kinase
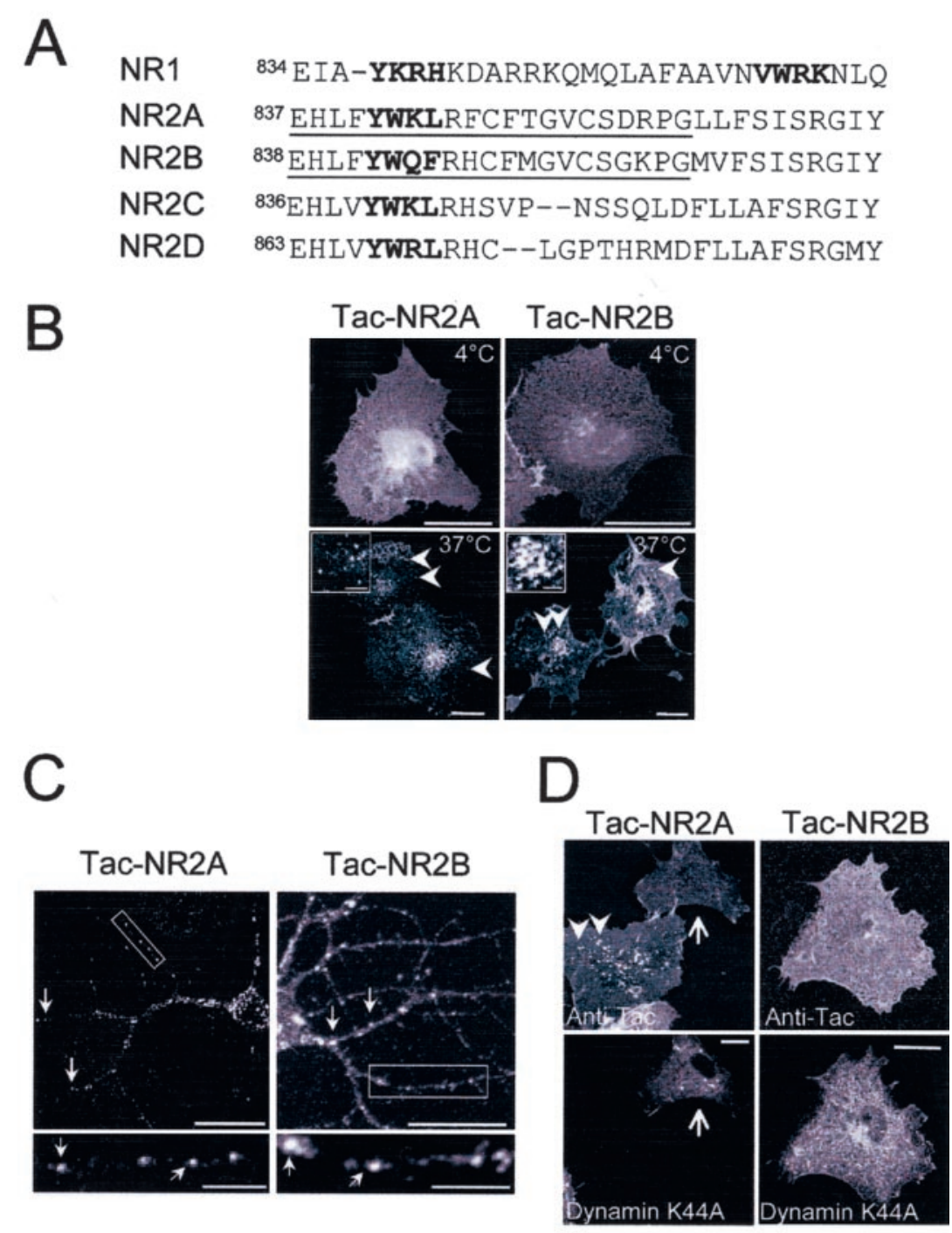

E

Tac-NR2A (Red)

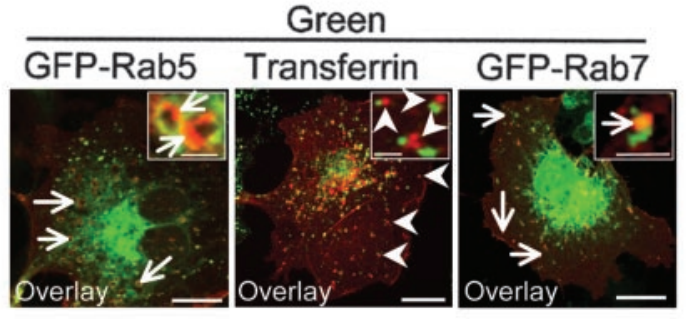

F

Green

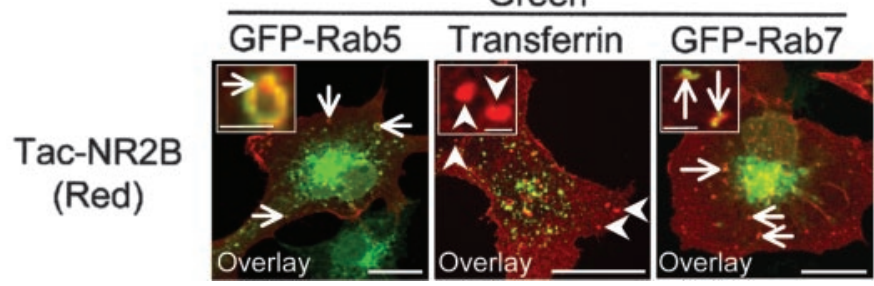

Figure 7. A conserved family of membrane-proximal endocytic signals in NMDA receptor subunits. $A$, The first 30 amino acids after the last transmembrane domain of NR1, NR2A, NR2B, NR2C, and NR2D are shown. Bold designates endocytic motifs identified in this study (NR1) or potential tyrosine-based endocytic motifs (NR2A-D). Underline designates the first 20 amino acids of NR2A or NR2B that were fused to Tac (Tac-NR2A, Tac-NR2B) and used in subsequent experiments. B, The membrane-proximal 20 amino acids of NR2A and NR2B contain an endocytic motif. Internalization assays were performed for 30 min at $37^{\circ} \mathrm{C}$ with an anti-Tac antibody on COS7 cells expressing Tac-NR2A or Tac-NR2B. Arrowheads indicate internalized receptors in Tac-NR2-expressing cells. Scale bars, $10 \mu \mathrm{m}$; insets, $1 \mu \mathrm{m}$. C, Tac-NR2A and Tac-NR2B are internalized in hippocampal neurons (10 DIV). Arrows indicate internalized Tac-NR2. Boxed regions are magnified in bottom panels. Scale bars, $10 \mu \mathrm{m}$; insets, $5 \mu \mathrm{m}$. D, (Figure legend continues.) 


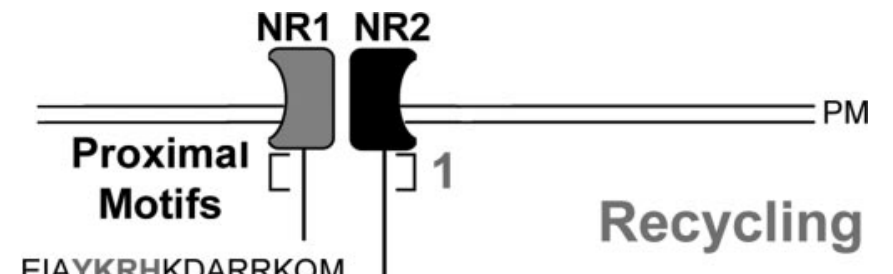

EIAYKRHKDARRKQM QLAFAAVNVWRKNLQ

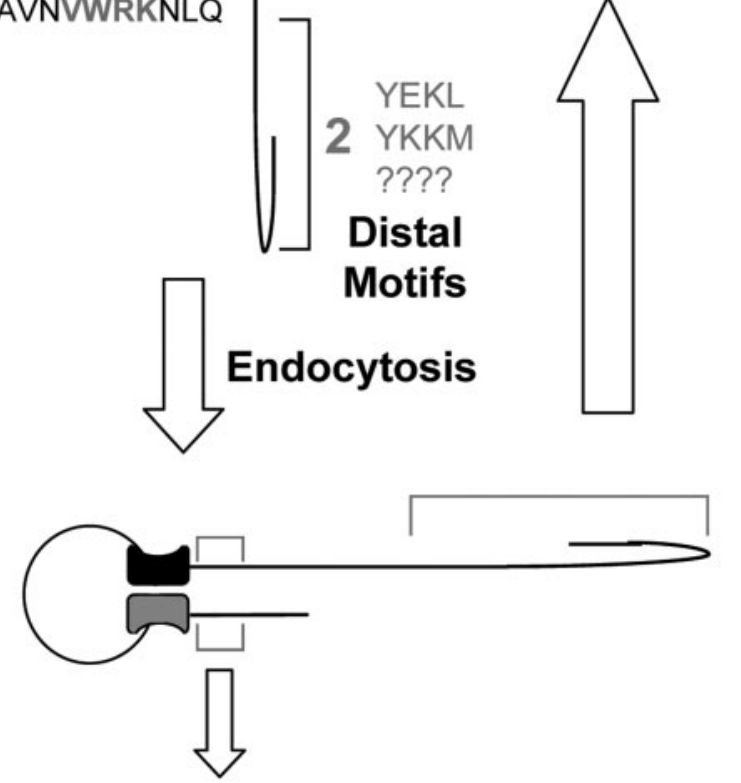

Late Endosome Lysosome \

\section{Degradation}

Figure 8. Model of NMDAR endocytic sorting and trafficking from the plasma membrane. NMDARs contain two distinct endocytic sorting domains: a membrane-proximal domain and a distal domain. Proximal endocytic signals located within both NR1 and NR2 subunits deliver receptors to late endosomes-lysosomes, where they are degraded. In contrast, endocytic motifs located within distal C-terminal domains of NR2B subunits drive receptors along a recycling pathway. The distinct location of these endocytic signals within the NMDAR molecule suggests differential regulation (see Discussion for details). PM, Plasma membrane.

type II) (Bayer et al., 2001; Leonard et al., 2002), indicating a role in assembling postsynaptic signaling complexes. Here, we have shown that the C0 domain regulates NMDAR endocytosis and degradative sorting. This remarkable convergence of regulatory mechanisms suggests that the membrane proximal $\mathrm{C} 0$ domain may act as an "integrator" of diverse cellular states, the readout of which is both NMDAR channel function and number. Indeed, both $\mathrm{Ca}^{2+}$ influx and actin remodeling are required for usedependent downregulation of synaptic NMDARs (Li et al., 2002), which is accompanied by a marked reduction in the number of NMDARs at the cell surface (Vissel et al., 2001; Li et al., 2002). Intriguingly, chelation of intracellular $\mathrm{Ca}^{2+}$ abolishes recovery from use-dependent rundown (Rosenmund and Westbrook, 1993b), perhaps by preventing $\mathrm{Ca}^{2+}$ - calmodulin binding to $\mathrm{C} 0$ and thereby preventing the steric masking of degradative sorting signals. Thus, it will be interesting to determine the role of $\mathrm{Ca}^{2+}$ dependent signals on the regulation of NMDAR degradative sorting.

\section{NMDAR sorting for recycling versus degradation}

An essential feature of excitatory synapse formation and maturation is the incorporation and stabilization of postsynaptic NMDARs (Goda and Davis, 2003). Here, we have shown that NMDARs possess distinct endocytic signals for trafficking to degradative and recycling pathways. Regulation of NMDAR sorting could provide a mechanism for maintaining NMDARs at synapses by preferential use of recycling sorting signals and for removing NMDARs from synapses by preferential use of degradative sorting signals. This sorting decision may in turn depend on cellular context, ligand binding, or receptor-associated proteins. For example, the binding of PDZ proteins such as NHERF/EBP50 $\left(\mathrm{Na}^{+}-\mathrm{H}^{+}\right.$exchanger regulatory factor $1 /$ ezrin-radixin-moesin binding phosphoprotein 50) or membrane-associated guanylate kinase inverted-2/synaptic scaffolding molecule (MAGI-2/SSCAM) to distal C-terminal domains regulates the sorting of G-protein-coupled receptors along recycling or degradative pathways (Cao et al., 1999; Xu et al., 2001). Interestingly, MAGI2/S-SCAM likewise binds the $\mathrm{C}$ terminus of NR2B (Xu et al., 2001) near a distal C-terminal endocytic motif (Roche et al., 2001), although its role in NMDAR sorting is not known. In the case of AMPARs, endocytosis and degradative sorting is triggered by ligand binding (Beattie et al., 2000; Ehlers, 2000; Lin et al., 2000), whereas recycling is stimulated by NMDAR-mediated $\mathrm{Ca}^{2+}$ influx and cAMP-dependent protein kinase (PKA) activity (Ehlers, 2000). Intriguingly, all AMPAR subunits contain a conserved membrane proximal tyrosine-based signature (YKSR) in a position that corresponds precisely with that of the YKRH late endosomal targeting motif in NR1. The function of the YKSR sequence in endocytosis or intracellular sorting of AMPARs is not known, but it is interesting to note that the C-terminal sequences required for NMDA-induced and ligand-induced endocytosis of AMPARs are distinct (Lee et al., 2002), with the sequence requirements for the latter yet to be determined. One possibility is that the membrane-proximal YKSR mediates ligand-induced AMPAR endocytosis. If so, juxtamembrane tyrosine-based motifs could provide a general mechanism for transducing ligand binding into endocytosis and lysosomal degradation that is conserved across the family of ionotropic glutamate receptors.
(Figure legend continued.) Internalization assays $\left(30 \mathrm{~min}, 37^{\circ} \mathrm{C}\right.$ ) were performed on COS7 cells expressing Tac-NR2A or Tac-NR2B along with dynamin-K44A. Note that dynamin-K44A prevents endocytosis. The arrow indicates a dynamin-K44A-expressing cell. Arrowheads indicate internalized receptors. Scale bars, $10 \mu \mathrm{m}$. E, The membrane-proximal domain of NR2A targets internalized receptors to late endosomes. Internalization assayswere performed on COS7 cells expressing Tac-NR2A as described in $B$. Arrows indicate localization to early endosomes (GFP-Rab5) $15 \mathrm{~min}$ after endocytosis (left panels). By 30-60 min after endocytosis, Tac-NR2A localized to late endosomes (GFP-Rab7; arrows, right panels) and did not colocalize with the recycling endocytic cargo Alexa-transferrin (arrowheads, middle panels). Scale bars, $10 \mu \mathrm{m}$; insets, $1 \mu \mathrm{m}$. $F$, The membrane-proximal domain of NR2B mediates transport to late endosomes. Internalization assays were performed on COS7 cells expressing Tac-NR2B as in $E$. The arrows indicate colocalization with GFP-Rab5 (left) and GFP-Rab7 (right). The arrowheads indicate the lack of colocalization with Alexa-transferrin after $60 \mathrm{~min}$ of endocytosis (middle panels). Scale bars, $10 \mu \mathrm{m}$; insets, $1 \mu \mathrm{m}$.

\section{References}

Abraham WC, Bear MF (1996) Metaplasticity: the plasticity of synaptic plasticity. Trends Neurosci 19:126-130.

Barria A, Malinow R (2002) Subunit-specific NMDA receptor trafficking to synapses. Neuron 35:345-353.

Bayer KU, De Koninck P, Leonard AS, Hell JW, Schulman H (2001) Interaction with the NMDA receptor locks CaMKII in an active conformation. Nature 411:801-805.

Beattie EC, Carroll RC, Yu X, Morishita W, Ya- 
suda H, von Zastrow M, Malenka RC (2000) Regulation of AMPA receptor endocytosis by a signaling mechanism shared with LTD. Nat Neurosci 3:1291-1300.

Bolshakov VY, Siegelbaum SA (1994) Postsynaptic induction and presynaptic expression of hippocampal long-term depression. Science 264:1148-1152.

Bonifacino JS, Traub LM (2003) Signals for sorting of transmembrane proteins to endosomes and lysosomes. Annu Rev Biochem 72:395-447.

Bredt DS, Nicoll RA (2003) AMPA receptor trafficking at excitatory synapses. Neuron 40:361-379.

Bresler T, Shapira M, Boeckers T, Dresbach T, Futter M, Garner CC, Rosenblum K, Gundelfinger ED, Ziv NE (2004) Postsynaptic density assembly is fundamentally different from presynaptic active zone assembly. J Neurosci 24:1507-1520.

Bucci C, Thomsen P, Nicoziani P, McCarthy J, van Deurs B (2000) Rab7: a key to lysosome biogenesis. Mol Biol Cell 11:467-480.

Cao TT, Deacon HW, Reczek D, Bretscher A, von Zastrow M (1999) A kinase-regulated PDZ-domain interaction controls endocytic sorting of the beta2-adrenergic receptor. Nature 401:286-290.

Carroll RC, Zukin RS (2002) NMDA-receptor trafficking and targeting: implications for synaptic transmission and plasticity. Trends Neurosci 25:571-577.

Carroll RC, Beattie EC, von Zastrow M, Malenka RC (2001) Role of AMPA receptor endocytosis in synaptic plasticity. Nat Rev Neurosci 2:315-324.

Chavrier P, Parton RG, Hauri HP, Simons K, Zerial M (1990) Localization of low molecular weight GTP binding proteins to exocytic and endocytic compartments. Cell 62:317-329.

Ehlers MD (2000) Reinsertion or degradation of AMPA receptors determined by activity-dependent endocytic sorting. Neuron 28:511-525.

Ehlers MD, Zhang S, Bernhadt JP, Huganir RL (1996) Inactivation of NMDA receptors by direct interaction of calmodulin with the NR1 subunit. Cell 84:745-755.

Friedman HV, Bresler T, Garner CC, Ziv NE (2000) Assembly of new individual excitatory synapses: time course and temporal order of synaptic molecule recruitment. Neuron 27:57-69.

Goda Y, Davis GW (2003) Mechanisms of synapse assembly and disassembly. Neuron 40:243-264.

Grosshans DR, Clayton DA, Coultrap SJ, Browning MD (2002) LTP leads to rapid surface expression of NMDA but not AMPA receptors in adult rat CA1. Nat Neurosci 5:27-33.

Heynen AJ, Quinlan EM, Bae DC, Bear MF (2000) Bidirectional, activitydependent regulation of glutamate receptors in the adult hippocampus in vivo. Neuron 28:527-536.

Hicke L, Dunn R (2003) Regulation of membrane protein transport by ubiquitin and ubiquitin-binding proteins. Annu Rev Cell Dev Biol 19:141-172.

Kneussel M (2002) Dynamic regulation of GABA(A) receptors at synaptic sites. Brain Res Brain Res Rev 39:74-83.

Kohr G, Jensen V, Koester HJ, Mihaljevic AL, Utvik JK, Kvello A, Ottersen OP, Seeburg PH, Sprengel R, Hvalby O (2003) Intracellular domains of NMDA receptor subtypes are determinants for long-term potentiation induction. J Neurosci 23:10791-10799.

Krapivinsky G, Krapivinsky L, Manasian Y, Ivanov A, Tyzio R, Pellegrino C, Ben-Ari Y, Clapham DE, Medina I (2003) The NMDA receptor is coupled to the ERK pathway by a direct interaction between NR2B and RasGRF1. Neuron 40:775-784.

Krupp JJ, Vissel B, Thomas CG, Heinemann SF, Westbrook GL (1999) Interactions of calmodulin and alpha-actinin with the NR1 subunit modulate $\mathrm{Ca}^{2+}$-dependent inactivation of NMDA receptors. J Neurosci 19:1165-1178.

Lavezzari G, McCallum J, Lee R, Roche KW (2003) Differential binding of the AP-2 adaptor complex and PSD-95 to the C-terminus of the NMDA receptor subunit NR2B regulates surface expression. Neuropharmacology 45:729-737.

Lee SH, Liu L, Wang YT, Sheng M (2002) Clathrin adaptor AP2 and NSF interact with overlapping sites of GluR2 and play distinct roles in AMPA receptor trafficking and hippocampal LTD. Neuron 36:661-674.

Legendre P, Rosenmund C, Westbrook GL (1993) Inactivation of NMDA channels in cultured hippocampal neurons by intracellular calcium. J Neurosci 13:674-684.

Leonard AS, Bayer KU, Merrill MA, Lim IA, Shea MA, Schulman H, Hell JW (2002) Regulation of calcium/calmodulin-dependent protein kinase II docking to $N$-methyl-D-aspartate receptors by calcium/calmodulin and alpha-actinin. J Biol Chem 277:48441-48448.

Li B, Chen N, Luo T, Otsu Y, Murphy TH, Raymond LA (2002) Differential regulation of synaptic and extra-synaptic NMDA receptors. Nat Neurosci 5:833-834.

Liao D, Zhang X, O’Brien R, Ehlers MD, Huganir RL (1999) Regulation of morphological postsynaptic silent synapses in developing hippocampal neurons. Nat Neurosci 2:37-43.

Lin JW, Ju W, Foster K, Lee SH, Ahmadian G, Wyszynski M, Wang YT, Sheng M (2000) Distinct molecular mechanisms and divergent endocytotic pathways of AMPA receptor internalization. Nat Neurosci 3:1282-1290.

Malinow R, Malenka RC (2002) AMPA receptor trafficking and synaptic plasticity. Annu Rev Neurosci 25:103-126.

Maxfield FR, McGraw TE (2004) Endocytic recycling. Nat Rev Mol Cell Biol 5:121-132.

McIlhinney RA, Le Bourdelles B, Molnar E, Tricaud N, Streit P, Whiting PJ (1998) Assembly intracellular targeting and cell surface expression of the human N-methyl-D-aspartate receptor subunits NR1a and NR2A in transfected cells. Neuropharmacology 37:1355-1367.

Mellman I (1996) Endocytosis and molecular sorting. Annu Rev Cell Dev Biol 12:575-625.

Meresse S, Gorvel JP, Chavrier P (1995) The rab7 GTPase resides on a vesicular compartment connected to lysosomes. J Cell Sci 108:3349-3358.

Montgomery JM, Madison DV (2002) State-dependent heterogeneity in synaptic depression between pyramidal cell pairs. Neuron 33: 765-777.

Mori H, Manabe T, Watanabe M, Satoh Y, Suzuki N, Toki S, Nakamura K, Yagi T, Kushiya E, Takahashi T, Inoue Y, Sakimura K, Mishina M (1998) Role of the carboxy-terminal region of the GluR epsilon2 subunit in synaptic localization of the NMDA receptor channel. Neuron 21:571-580.

Mu Y, Otsuka T, Horton AC, Scott DB, Ehlers MD (2003) Activitydependent mRNA splicing controls ER export and synaptic delivery of NMDA receptors. Neuron 40:581-594.

Mukherjee S, Ghosh RN, Maxfield FR (1997) Endocytosis. Physiol Rev 77:759-803.

Nong Y, Huang YQ, Ju W, Kalia LV, Ahmadian G, Wang YT, Salter MW (2003) Glycine binding primes NMDA receptor internalization. Nature 422:302-307.

Okabe S, Miwa A, Okado H (1999) Alternative splicing of the C-terminal domain regulates cell surface expression of the NMDA receptor NR1 subunit. J Neurosci 19:7781-7792.

Oliet SH, Malenka RC, Nicoll RA (1997) Two distinct forms of long-term depression coexist in CA1 hippocampal pyramidal cells. Neuron 18:969-982.

Philpot BD, Sekhar AK, Shouval HZ, Bear MF (2001) Visual experience and deprivation bidirectionally modify the composition and function of NMDA receptors in visual cortex. Neuron 29:157-169.

Philpot BD, Espinosa JS, Bear MF (2003) Evidence for altered NMDA receptor function as a basis for metaplasticity in visual cortex. J Neurosci 23:5583-5588.

Prybylowski K, Fu Z, Losi G, Hawkins LM, Luo J, Chang K, Wenthold RJ, Vicini S (2002) Relationship between availability of NMDA receptor subunits and their expression at the synapse. J Neurosci 22: 8902-8910.

Quinlan EM, Philpot BD, Huganir RL, Bear MF (1999) Rapid, experiencedependent expression of synaptic NMDA receptors in visual cortex in vivo. Nat Neurosci 2:352-357.

Rao A, Craig AM (1997) Activity regulates the synaptic localization of the NMDA receptor in hippocampal neurons. Neuron 19:801-812.

Roche KW, Standley S, McCallum J, Dune Ly C, Ehlers MD, Wenthold RJ (2001) Molecular determinants of NMDA receptor internalization. Nat Neurosci 4:794-802.

Rosenmund C, Westbrook GL (1993a) Calcium-induced actin depolymerization reduces NMDA channel activity. Neuron 10:805-814.

Rosenmund C, Westbrook GL (1993b) Rundown of N-methyl-D-aspartate channels during whole-cell recording in rat hippocampal neurons: role of $\mathrm{Ca}^{2+}$ and ATP. J Physiol (Lond) 470:705-729.

Scott DB, Blanpied TA, Swanson GT, Zhang C, Ehlers MD (2001) An NMDA receptor ER retention signal regulated by phosphorylation and alternative splicing. J Neurosci 21:3063-3072.

Scott DB, Blanpied TA, Ehlers MD (2003) Coordinated PKA and PKC phosphorylation suppresses RXR-mediated ER retention and regulates 
the surface delivery of NMDA receptors. Neuropharmacology 45:755-767.

Snyder EM, Philpot BD, Huber KM, Dong X, Fallon JR, Bear MF (2001) Internalization of ionotropic glutamate receptors in response to mGluR activation. Nat Neurosci 4:1079-1085.

Sonnichsen B, De Renzis S, Nielsen E, Rietdorf J, Zerial M (2000) Distinct membrane domains on endosomes in the recycling pathway visualized by multicolor imaging of Rab4, Rab5, and Rab11. J Cell Biol 149:901-914.

Sprengel R, Suchanek B, Amico C, Brusa R, Burnashev N, Rozov A, Hvalby O, Jensen V, Paulsen O, Andersen P, Kim JJ, Thompson RF, Sun W, Webster LC, Grant SG, Eilers J, Konnerth A, Li J, McNamara JO, Seeburg PH (1998) Importance of the intracellular domain of NR2 subunits for NMDA receptor function in vivo. Cell 92:279-289.

Standley S, Roche KW, McCallum J, Sans N, Wenthold RJ (2000) PDZ domain suppression of an ER retention signal in NMDA receptor NR1 splice variants. Neuron 28:887-898.

Steigerwald F, Schulz TW, Schenker LT, Kennedy MB, Seeburg PH, Kohr G (2000) C-Terminal truncation of NR2A subunits impairs synaptic but not extrasynaptic localization of NMDA receptors. J Neurosci 20:4573-4581.

Tan PK, Waites C, Liu Y, Krantz DE, Edwards RH (1998) A leucine-based motif mediates the endocytosis of vesicular monoamine and acetylcholine transporters. J Biol Chem 273:17351-17360.

Tjelle TE, Brech A, Juvet LK, Griffiths G, Berg T (1996) Isolation and characterization of early endosomes, late endosomes and terminal lysosomes: their role in protein degradation. J Cell Sci 109:2905-2914.

Turrigiano GG, Leslie KR, Desai NS, Rutherford LC, Nelson SB (1998) Activity-dependent scaling of quantal amplitude in neocortical neurons. Nature 391:892-896.

Vissel B, Krupp JJ, Heinemann SF, Westbrook GL (2001) A use-dependent tyrosine dephosphorylation of NMDA receptors is independent of ion flux. Nat Neurosci 4:587-596.

Vitelli R, Santillo M, Lattero D, Chiariello M, Bifulco M, Bruni CB, Bucci C (1997) Role of the small GTPase Rab7 in the late endocytic pathway. J Biol Chem 272:4391-4397.

von Zastrow M, Svingos A, Haberstock-Debic H, Evans C (2003) Regulated endocytosis of opioid receptors: cellular mechanisms and proposed roles in physiological adaptation to opiate drugs. Curr Opin Neurobiol 13:348-353.

Wang YT, Pak YS, Salter MW (1993) Rundown of NMDA-receptor mediated currents is resistant to lowering intracellular $\left[\mathrm{Ca}^{2+}\right]$ and is prevented by ATP in rat spinal dorsal horn neurons. Neurosci Lett 157:183-186.

Washbourne P, Bennett JE, McAllister AK (2002) Rapid recruitment of NMDA receptor transport packets to nascent synapses. Nat Neurosci 5:751-759.

Watt AJ, van Rossum MC, MacLeod KM, Nelson SB, Turrigiano GG (2000) Activity coregulates quantal AMPA and NMDA currents at neocortical synapses. Neuron 26:659-670.

Wenthold RJ, Prybylowski K, Standley S, Sans N, Petralia RS (2003) Trafficking of NMDA receptors. Annu Rev Pharmacol Toxicol 43:335-358.

Westphal RS, Tavalin SJ, Lin JW, Alto NM, Fraser ID, Langeberg LK, Sheng M, Scott JD (1999) Regulation of NMDA receptors by an associated phosphatase-kinase signaling complex. Science 285:93-96.

Wiley HS, Burke PM (2001) Regulation of receptor tyrosine kinase signaling by endocytic trafficking. Traffic 2:12-18.

Wyszynski M, Lin J, Rao A, Nigh E, Beggs AH, Craig AM, Sheng M (1997) Competitive binding of alpha-actinin and calmodulin to the NMDA receptor. Nature 385:439-442.

Xia H, Hornby ZD, Malenka RC (2001) An ER retention signal explains differences in surface expression of NMDA and AMPA receptor subunits. Neuropharmacology 41:714-723.

Xu J, Paquet M, Lau AG, Wood JD, Ross CA, Hall RA (2001) beta 1 -adrenergic receptor association with the synaptic scaffolding protein membrane-associated guanylate kinase inverted-2 (MAGI-2). Differential regulation of receptor internalization by MAGI-2 and PSD-95. J Biol Chem 276:41310-41317.

Zerial M, McBride H (2001) Rab proteins as membrane organizers. Nat Rev Mol Cell Biol 2:107-117.

Zhang S, Ehlers MD, Bernhardt JP, Su CT, Huganir RL (1998) Calmodulin mediates calcium-dependent inactivation of $N$-methyl-D-aspartate receptors. Neuron 21:443-453.

Zukin RS, Bennett MV (1995) Alternatively spliced isoforms of the NMDARI receptor subunit. Trends Neurosci 18:306-313. 